\title{
CHEK2 SIGNALING IS THE KEY REGULATOR OF OOCYTE SURVIVAL AFTER CHEMOTHERAPY
}

\author{
Chihiro Emori ${ }^{1,2}$, Zachary Boucher ${ }^{1}$, Ewelina Bolcun-Filas ${ }^{1 \#}$ \\ ${ }^{1}$ The Jackson Laboratory, 600 Main Street, Bar Harbor, ME 04609, USA. \\ ${ }^{2}$ Department of Experimental Genome Research, Research Institute for Microbial Diseases, Osaka University, Suita, Osaka \\ 5650871, Japan. \\ \#Corresponding author: Ewelina.Bolcun-Filas@jax.org
}

\begin{abstract}
Radiation and chemotherapy can damage the primordial follicle reserve in female cancer patients leading to ovarian failure and infertility. Preservation of ovarian function requires treatment strategies that prevent loss of immature oocytes in primordial follicles during cancer therapy. Checkpoint kinase 2 (CHEK2) inhibition prevents loss of primordial oocytes caused by DNA damage and thus is a promising target for ovoprotective treatment against genotoxic agents. To determine which cancer treatments could benefit from ovoprotective activity of CHEK2 inhibition we investigated oocyte survival in Chek2-/- mice exposed to different chemotherapy drugs. Here, we show that loss of CHEK2 function prevents elimination of primordial oocytes damaged by cisplatin, cyclophosphamide, mafosfamide, doxorubicin, and etoposide, suggesting it could be used to reduce ovarian damage caused by wide range of drugs. Using genetic knockouts we reveal a critical role for TRP53 in oocyte response to chemotherapy drugs and show that both targets of CHEK2 - TAp63 and TRP53 are activated by cisplatin and cyclophosphamide. Furthermore, we show that checkpoint kinase inhibitor and radiation- and chemotherapy sensitizer AZD7762 reduces oocyte elimination after radiation and chemotherapy treatments, despite its cytotoxic effect on ovarian somatic cells. Altogether, these findings demonstrate the role for CHEK2 as the master regulator of primordial oocyte survival or death and credential its targeting for ovoprotective treatments.
\end{abstract}

\section{INTRODUCTION}

Women are born with a finite supply of the oocytes that ultimately form the eggs that are ovulated. The primordial oocytes are enclosed in primordial follicles (PMF) which must survive and last through a woman's entire reproductive life. PMFs decrease naturally with age until menopause, which occurs when follicle supplies become depleted. Studies in human and animal models show that various environmental factors-such as pollutants, smoking, diet, etc. - can diminish ovarian follicle reserve (1-4). Importantly, now that diagnosis and treatment of cancers is more efficient, the ovarian follicle reserve can also be damaged in females patients by cancer treatments leading to accelerated PMF loss and resulting in infertility and premature ovarian insufficiency (POI) (1,5-7). Treatment-induced-POI results in early menopause, an endocrine deficiency associated with osteoporosis, cardiovascular disorders, depression, and other comorbidities that require medical attention and can negatively impact the quality of survivorship (8-11). Quality of life considerations are especially important for pediatric, adolescent, and young adult cancer survivors due to their long-life expectancy. The overall prevalence of POI varies considerably $(6-80 \%)$ due to heterogeneity

\section{SIGNIFICANCE}

Chemotherapy and radiation are ovotoxic and increase the risk of premature ovarian insufficiency and infertility in women cancer survivors. Development of treatment strategies preserving ovarian function and ensuring future reproductive health of female cancer patients depends on better understanding of the mechanisms underlying ovarian toxicity caused by different chemotherapy treatments. Preservation of long-term ovarian function can only be achieved by preventing the loss of immature oocytes in primordial follicles during toxic cancer therapies. Checkpoint kinase 2 (CHEK2) inhibition is an attractive strategy for protecting ovarian reserve with a potential additional benefit of sensitizing cancer cells to radiation and chemotherapy. Using a genetic approach, we show that blocking CHEK2 function is sufficient to prevent elimination of primordial oocytes damaged by chemotherapy drugs such as cisplatin, cyclophosphamide, mafosfamide, doxorubicin and etoposide. Many chemotherapy drugs are used in combination (e.g. cyclophosphamide with doxorubicin), thus the protective effect of CHEK2 inhibition is likely to be beneficial for a broad spectrum of patient treatments. 
of cancers and treatments $(9,12-17)$. Fertility preservation methods, such as cryopreservation of eggs and embryos, are available for cancer patients of reproductive age; however, these methods are not available to prepubertal girls (18-20). Currently, ovarian tissue cryopreservation is the only fertility preservation method for prepubertal girls, but it does not prevent POI (21-24). There are currently no proven methods to protect ovaries from systemic chemotherapies during ongoing treatments in young patients.

Genotoxic cancer treatments kill cancer cells by inducing DNA damage, which is more detrimental to fast dividing cancer cells than healthy cells. However, these treatments can also damage healthy cells including oocytes. DNA damage inflicted in oocytes in PMFs seems to be the major trigger of radiation- and chemotherapy-induced PMF elimination (25-27); therefore, a strategy blocking the DNA damage response (DDR) in oocytes offers an attractive strategy to prevent PMF loss and POI. In contrast, growing oocytes in primary and secondary follicles are not as susceptible to DNA damage (28). This suggests a different response mechanism in the growing oocyte after follicle activation or a role for supporting granulosa cells within the follicle.

Why primordial oocytes, which are arrested at meiotic prophase I and are not replicating, are sensitive to chemotherapy drugs that interfere with DNA replication and transcription is still poorly understood. The most lethal type of DNA damage-DNA Double Strand Breaks (DSB)-leads to activation of CHEK2. CHEK2 coordinates DDR through activation of TRP53 (also known as p53) which leads to cell cycle arrest, senescence, or apoptosis depending on the cell type and cell cycle phase (29-31). In contrast, in primordial oocytes, CHEK2 predominantly activates a TRP53related protein TRP63 - and specifically its TA isoform (henceforth TAp63)-leading to oocyte elimination $(26,28,32)$. Genetic inactivation of TAp63 protects primordial oocytes from cisplatin-induced damage but not from cyclophosphamide $(33,34)$. These differences in survival suggest involvement of other DDR proteins (i.e., CHEK1) in the primordial oocyte response to different chemotherapy drugs. Studies utilizing kinase inhibitors known to target both CHEK1 and CHEK2 reported their protective effects in primordial oocytes against cisplatin, cyclophosphamide, and doxorubicin toxicity $(32,34,35)$. However due to concerns about target specificity of these inhibitors it remains unclear which of the CHEK kinases responds to each chemotherapy drug. Considering the potential use of CHEK2 inhibitors for primordial oocyte protection, more information is needed regarding CHEK2 and its downstream effectors in chemotherapy-induced oocyte loss to identify cancer treatments which could benefit from oocyte-protective activity of CHEK2 inhibitors. Furthermore, better understanding of the cellular damage and related response mechanisms leading to primordial oocyte death will provide insight into the maintenance of the ovarian reserve in women exposed to other exogenous ovotoxic agents.

Our previous studies showed that genetic inactivation of CHEK2 prevents PMF loss in mice after exposure to ionizing radiation (26). In this study, we use wildtype and CHEK2-deficient mice to determine the role of CHEK2 in oocyte elimination in response to chemotherapyinduced damage and if inactivation of CHEK2 or its downstream effectors is sufficient to prevent chemotherapy-induced loss of PMFs. We provide genetic evidence that suggests CHEK2 inhibition is sufficient to protect primordial oocytes from alkylating agents cisplatin (CDDP) and cyclophosphamide (CTX), and topoisomerase II poisons doxorubicin (DOX) and etoposide (ETO). Moreover, we present genetic evidence that both TAp63 and TRP53 are involved in elimination of primordial oocytes damaged by CTX and CDDP. We also show that cancer sensitizing agent and CHEK $1 / 2$ inhibitor AZD7762 can protect oocytes from radiation and chemotherapy induced damage. The results of this study highlight the importance of targeted development of new inhibitors specific to CHEK2 to prevent PMF loss during cancer treatments.

\section{RESULTS}

\section{Inactivation of CHEK2 prevents oocyte elimination caused by chemotherapy drugs in ex vivo organ culture.}

Previous studies showed that genetic and pharmacological inactivation of CHEK2 prevents POI in mice after exposure to radiation $(26,36)$. Additional studies using the CHEK2 inhibitor BML-277 showed a protective effect against the chemotherapy drugs CDDP, DOX, and CTX derivative 4-HC $(32,34,35)$. However, it remains unclear whether this protective effect is due to inhibition of CHEK2 or CHEK1 kinases due to concerns about inhibitor specificity (34). To test the direct role of CHEK2 in elimination of PMFs damaged by genotoxic chemotherapy drugs and determine if CHEK2 inhibition would be effective and sufficient in reducing PMF loss, we tested how genetic ablation of CHEK2 function affects primordial oocyte survival after treatments. We chose chemotherapy drugs known to induce DNA damage via different mechanisms and characterized by different severities of ovarian adverse effects: DNA alkylating agents CDDP and mafosfamide (MAFO; an analog of CTX (37)), and DNA topoisomerase II poisons DOX and ETO $(33,38-41)$. We used MAFO in ex vivo culture to imitate the in vivo activity of CTX, which needs to be metabolized by the liver to generate metabolites with alkylating properties $(37,42)$. To better control for 

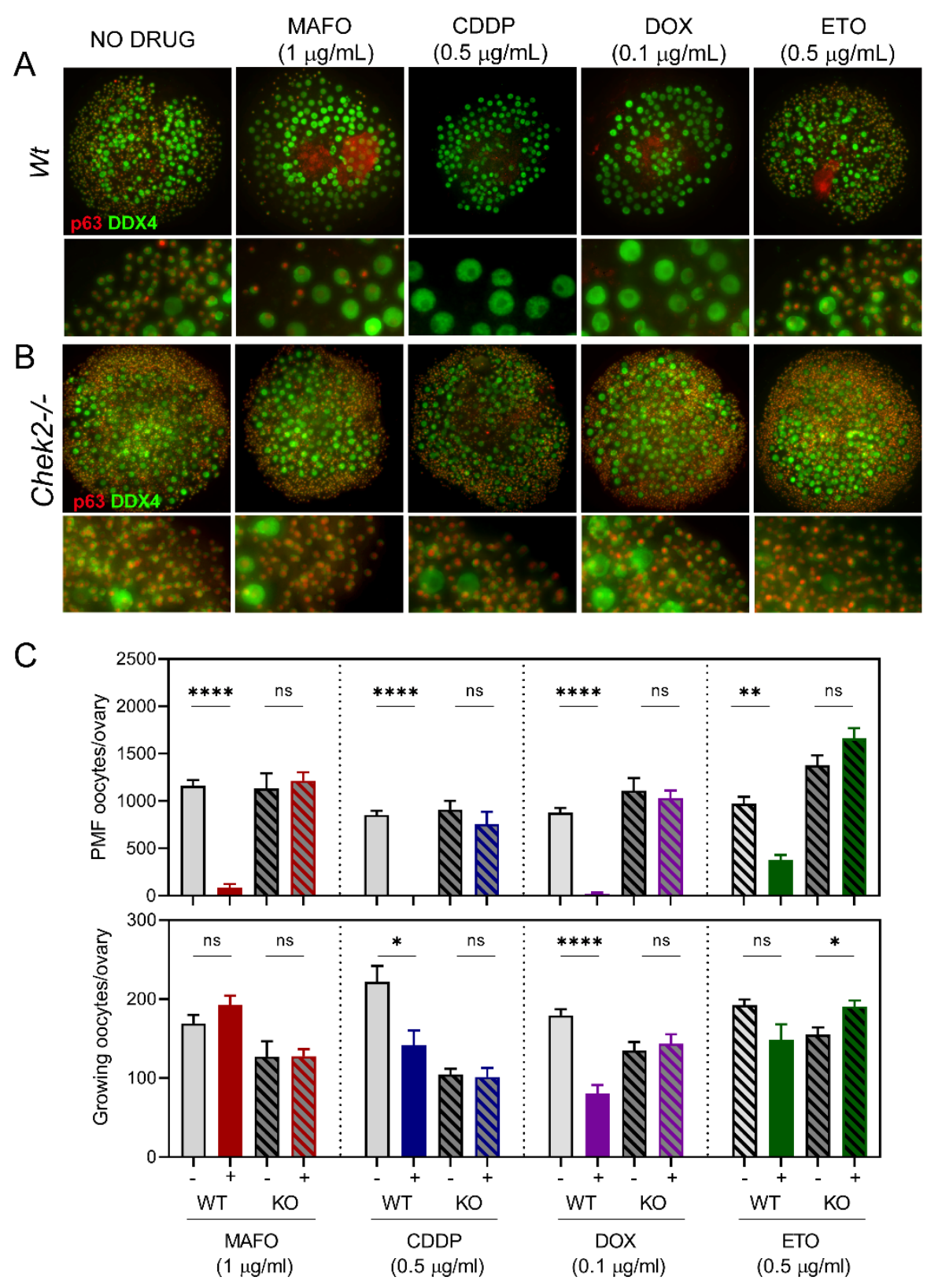

Figure. 1 CHEK2 deficiency prevents primordial oocyte depletion after ex vivo treatment with MAFO, CDDP, DOX and ETO. Ovaries from wildtype (A) and Chek2-/- females after 7-day ex vivo culture with MAFO (1 $\mu \mathrm{g} / \mathrm{mL})$, CDDP (0.5 $\mu \mathrm{g} / \mathrm{mL})$, $\operatorname{DOX}(0.1 \mu \mathrm{g} / \mathrm{mL})$ or ETO $(0.5 \mu \mathrm{g} / \mathrm{mL})$ were immunostained for oocyte markers DDX4 and p63. Whole ovaries are shown on top and magnified regions below. (C) Primordial and growing oocytes were counted in ovaries harvested after 7-day organ culture. Primordial oocytes are found in PMFs and growing oocytes are found in primary and secondary follicles. Data are expressed as mean \pm SEM; $* \mathrm{p}<0.05, * * \mathrm{p}<0.01, * * * \mathrm{p}<0.001, * * * * \mathrm{p}<0.0001$ (Mann-Whitney nonparametric test).

effective drug doses and duration of exposure for comparative analysis we utilized ex vivo organ culture system, where we cultured whole ovaries to prevent potential PMF activation due to fragmentation of ovarian tissue (43). We used ovaries from one-week-old females, the stage at which mouse ovaries predominantly contain fully formed PMFs and small population of primary/secondary follicles. This approach also facilitates investigation of direct toxicity of primordial oocytes without the potential confounding effects from damage to growing follicles seen in post-pubertal females. Ovaries were cultured for five days after completion of 48 hours drug treatment, or a total of one week, to ensure observation of long-term primordial oocyte survival rather than delay in apoptosis. To determine doses that significantly deplete primordial oocytes, we exposed ovarian explants from wildtype females to increasing doses of MAFO $(0.1-1 \mu \mathrm{g} / \mathrm{ml})$, CDDP $(0.1-0.5 \mu \mathrm{g} / \mathrm{ml})$, DOX $(0.025-0.1 \mu \mathrm{g} / \mathrm{ml})$ and ETO $(0.05-0.5 \mu \mathrm{g} / \mathrm{ml})$ (Fig. $\mathrm{S} 1)$. The number of primordial oocytes was reduced compared to vehicle controls following exposure to all tested drugs in a dose dependent manner (Fig. S1). 
Significantly reduced survival of primordial oocytes was observed in wildtype ovaries for MAFO at $1 \mu \mathrm{g} / \mathrm{ml}(7.3 \%$ $\pm 9.0 ; \mathrm{P}<0.0001), \mathrm{CDDP}$ at $0.5 \mu \mathrm{g} / \mathrm{ml}(0.04 \% \pm 0.08$; $\mathrm{P}<0.0001)$ and DOX at $0.1 \mu \mathrm{g} / \mathrm{ml}(0.8 \% \pm 0.6 ; \mathrm{P}$ $<0.0001$ ), and to lesser extent for ETO at $0.5 \mu \mathrm{g} / \mathrm{ml}$ $(39.0 \% \pm 13.7 ; \mathrm{P}=0.0021)$ (Fig. 1 A,C). In agreement with published data, ETO showed lowest toxicity in juvenile ovaries, suggesting mechanistic differences in toxicity compared to the other topoisomerase II poison tested (DOX). When Chek2-/- ovaries were treated with the same doses of drugs no significant reduction in primordial oocyte numbers was observed (Fig. 1A, B, C). We calculated oocyte survival as a percentage of ovarian reserve in untreated wildtype and Chek2-/- females. When compared to wildtype controls, survival of primordial oocytes lacking CHEK2 was improved after MAFO (7.3\% vs. $107.3 \% ; \mathrm{P}=0.0002), \mathrm{CDDP}(0.04 \%$ vs. $83.2 \%$; $\mathrm{P}<0.0001)$, DOX (2.4\% vs. $92.9 \% ; \mathrm{P}<0.0001)$ and ETO (39\% vs. $120.7 \% ; \mathrm{P}=0.0006)$.

Because there have been reports that CDDP and CTX induce hyperactivation of PMFs and their transition to growing follicles (44-46), we counted the larger growing oocytes (diameter $>30 \mu \mathrm{m}$ ), which are typically found in primary and secondary follicles, in 2-week old ovaries treated with each of the four drugs. We observed no significant increase in growing oocyte numbers: to the contrary, in some cases (CDDP, DOX), we observed a reduction in the number of growing oocytes after drug treatments (Fig. 1C, Fig. S1). This indicates that follicle hyperactivation is not the major mechanism of PMF loss in prepubertal ovaries or ex vivo explants and is in agreement with other studies $(35,47,48)$. It is possible that MAFO (an analog of CTX) has a different effect on ovaries ex vivo than CTX in vivo, however both drugs have been shown to generate similar metabolites $(37,42)$. In summary, survival of oocytes in Chek2 -/- treated ovaries ex vivo demonstrate that CHEK2 is directly responsible for elimination of PMFs after treatment with four different chemotherapy drugs and that CHEK2 inhibition is likely sufficient to prevent loss of PMF reserve in cancer patients treated with these drugs.

\section{CHEK2 deficiency prevents PMF loss after in vivo treatment with an acute dose of alkylating chemotherapy drugs.}

To confirm that abrogation of CHEK2 activity is sufficient to mitigate chemotherapy-induced PMF loss in prepuberal mouse ovaries in vivo, one-week-old control (Chek2+/-) and Chek2-/- females were treated with vehicle or an acute dose of CTX $(150 \mathrm{mg} / \mathrm{kg})$ or CDDP $(5$ $\mathrm{mg} / \mathrm{kg}$ ); both of which are highly ovotoxic $(14,41)$ $(49,50)$. Female weights were recorded before treatment and then weekly until ovaries were collected at week three (two weeks post-treatment) for histological analyses of
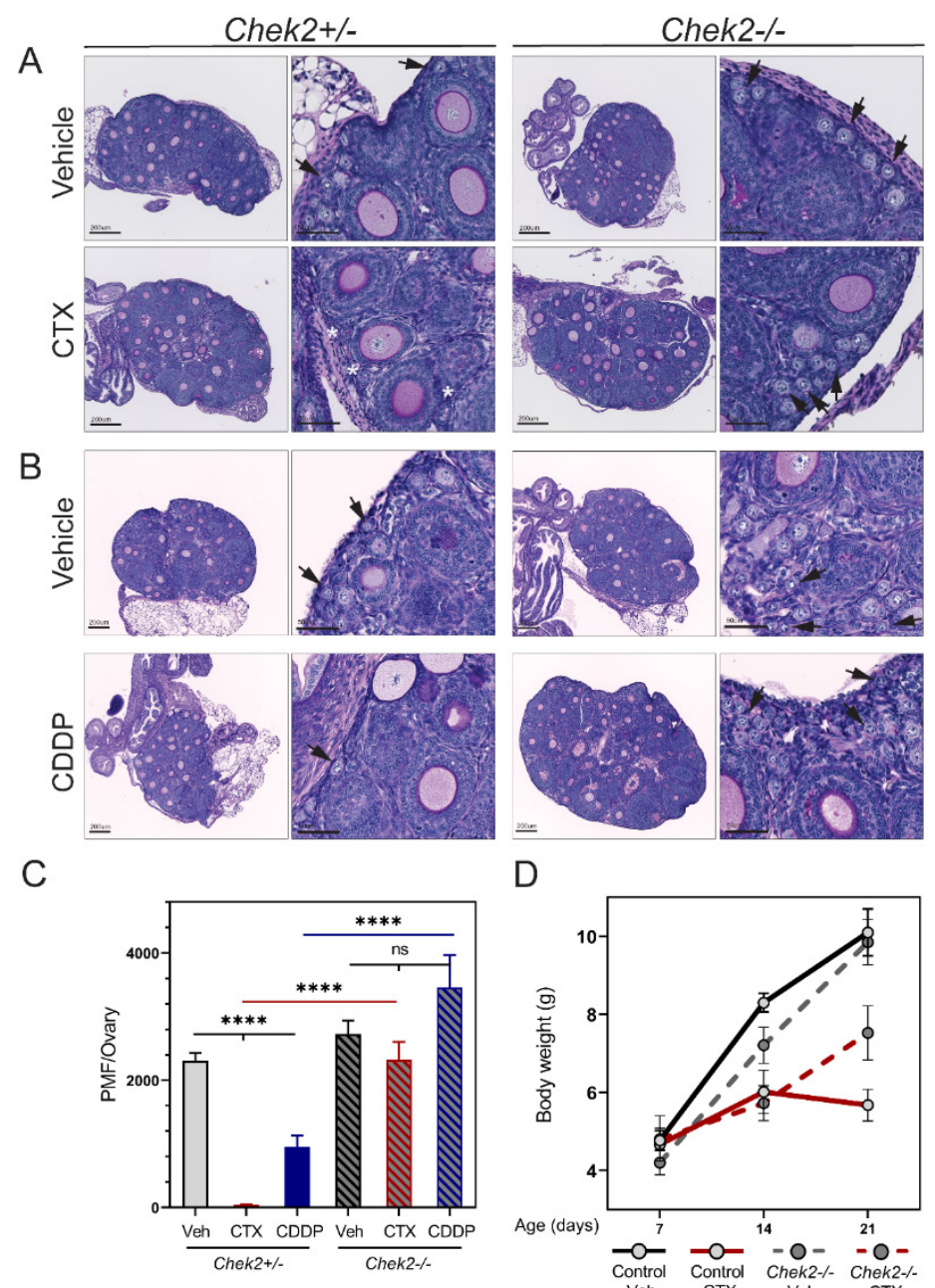

B

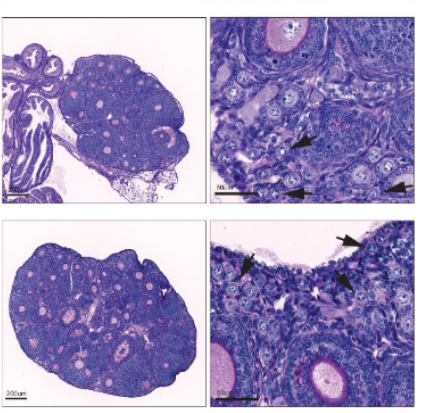

D

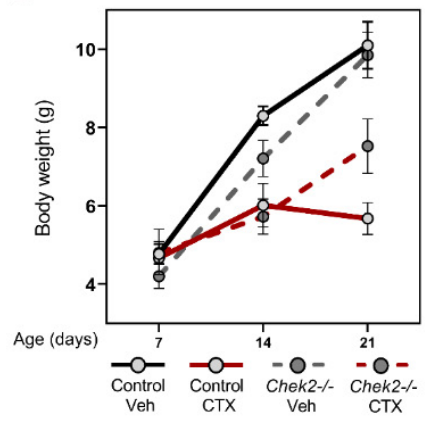

Figure 2. CHEK2 deficient females maintain PMF reserve after in vivo treatment with $\mathrm{CTX}$ and CDDP. Ovarian histology from Chek2+/- and Chek2-/- females two weeks after in vivo treatment with cyclophosphamide CTX $(150 \mathrm{mg} / \mathrm{kg})(\mathrm{A})$ and CDDP $(5 \mathrm{mg} / \mathrm{kg})(\mathrm{B})$. Arrows indicate PMFs and asterisks follicle remnants devoid of oocytes. (C) PMF numbers counted in Chek2+/- and Chek2-/- ovaries 2 weeks post treatment with drugs. (D) Body weight changes in Chek2+/- and Chek2-/- females treated with CTX. Data are expressed as mean $\pm \mathrm{SEM} ;{ }^{*} \mathrm{p}<0.05, \quad * * \mathrm{p}<0.01$, $* * * \mathrm{p}<0.001,{ }^{* * * *} \mathrm{p}<0.0001$ (Mann-Whitney nonparametric test).

the PMF reserve. CTX treatment obliterated oocytes in PMF in control females (Fig. 2A,C), while abundant PMFs with oocytes were present in ovaries from CTX treated Chek2-/- females (3\% vs. 91\%; $\mathrm{P}<0.0001)$ (Fig. 2A,C). CDDP treatment significantly decreased PMF numbers in ovaries from control animals while abundant PMFs were present in Chek2-/- females (37\% vs 100\%; P $=0.0009)$ (Fig. 2 B,C). Moreover, improved weight gain was evident in treated Chek2-/- pups compared to controls (60\% vs. $10 \%$ ) (Fig. 2D), suggesting that inhibition of CHEK2 activity could potentially alleviate other adverse side effects caused by CTX, although hair loss associated with CTX treatment was not prevented (data not shown). 
CTX and CDDP treated Chek2-/- females retained $>90 \%$ of their ovarian reserve and showed healthy growing follicles in the ovary at 3 weeks of age, thus were expected to be fertile. In this study we focused on PMF survival rather than fertility outcomes but other studies indicate that oocytes that survive genotoxic treatments can produce healthy offspring $(33,34)$. Taken together, these results indicate that targeting CHEK2 activity in vivo is sufficient to protect against CDDP and CTX induced PMF loss.

CDDP and MAFO treatments cause DNA DSBs in oocytes, which exhibit markers for homologous recombination but not non-homologous end joining repair.

CHEK2 has been shown to coordinate elimination of oocytes in response to unrepaired, programmed meiotic and radiation-induced DSBs $(26,51)$. To examine whether the four tested drugs cause DNA DSBs in oocytes, which would activate CHEK2 signaling, vehicle- and drugtreated wildtype ovaries were immunostained for general DNA DSB marker $\gamma-\mathrm{H} 2 \mathrm{AX}$. After 24 hours of treatment, abundant $\gamma-\mathrm{H} 2 \mathrm{AX}$ foci were present in oocytes treated with MAFO and CDDP but not with DOX or ETO (Fig. $3 \mathrm{~A}, \mathrm{D})$. Since DSB can be repaired by high fidelity homologous recombination (HR) or more error-prone non-homologous end joining (NHEJ), ovaries were immunostained for HR marker RAD51 and NHEJ marker $53 \mathrm{bp} 1$.

RAD51 foci were present in oocytes treated with MAFO or CDDP, indicating that these drugs activate the HR repair pathway (Fig. 3B, E). There were no RAD51 foci in DOX and ETO treated oocytes, consistent with the $\gamma$ H2AX staining results (Fig. 3B, E). Oocytes in postnatals ovaries are arrested at dictyate stage of meiotic prophase I, comparable to mitotic G2 phase. In this phase, HR is believed to be the predominant repair pathway due to the presence of sister chromatids, but NHEJ repair is also thought to be active. A previous report shows that DNAPKcs, a component of NHEJ repair, is detected in only $10 \%$ of primordial oocytes after radiation-induced DNA damage (52). Another study reported DNA-PKcs activation in 30-60\% of oocytes after CTX treatment (53). To determine the activation of NHEJ in oocytes after chemotherapy, ovaries were immunostained with 53BP1(Fig. 3C) (54,55). 53BP1directs DSB repair towards NHEJ and localizes to DSB sites forming discrete foci that colocalize with $\gamma$-H2AX (54-56). Remarkably, there was no evidence for 53BP1 foci in oocytes treated with any of our tested chemotherapy drugs. However, they were readily detected in somatic cells in the ovary (Fig. 3C). This indicates that DNA damage in oocytes is predominantly, if not exclusively, repaired by high fidelity HR, which has lower risk of generating deleterious mutations, as was shown for radiation (52).

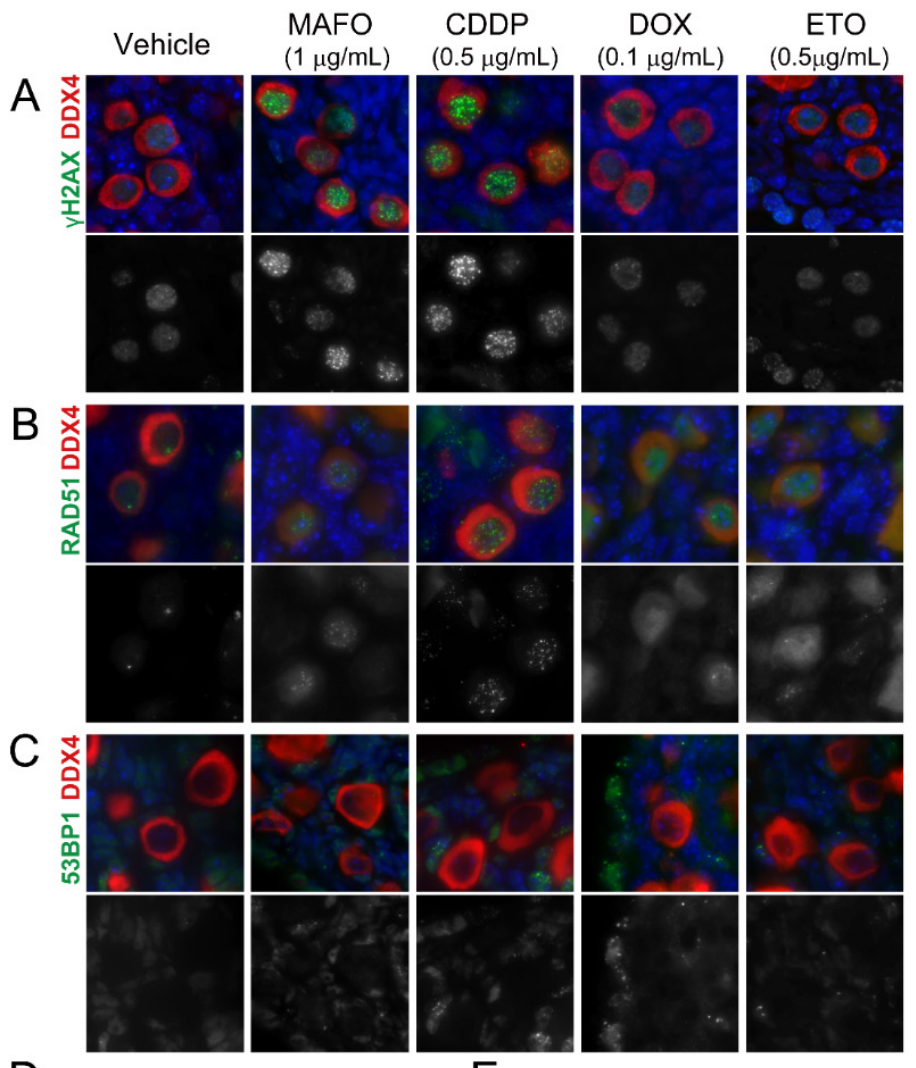

D

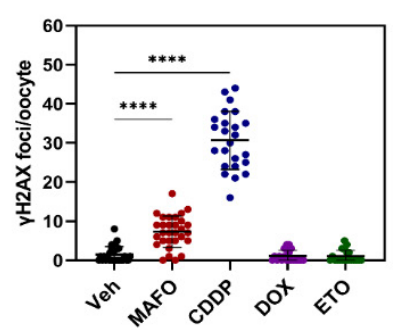

$\mathrm{E}$

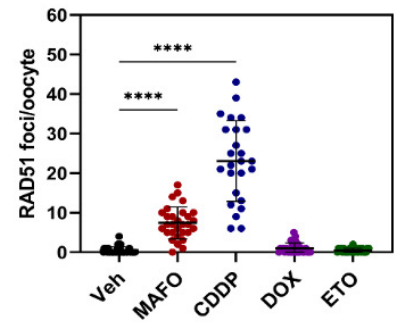

Figure 3. MAFO and CDDP treatment of oocytes causes DNA DSBs that activate HR, but not NHEJ, repair. Ovaries were exposed to chemotherapy drugs ex vivo for 24 hrs. Ovarian sections were immunostained for (A) general DNA damage marker $\gamma \mathrm{H} 2 \mathrm{AX}$ and DNA repair markers (B) RAD51 for HR and (C) 53BP1 for NHEJ. Quantification of DSBs per oocyte using (D) $\gamma \mathrm{H} 2 \mathrm{AX}$ and (C) RAD51 markers. Data are expressed as mean \pm SEM; ${ }^{*} p<0.05,{ }^{* *} p<0.01$, $* * * p<0.001, * * * * p<0.0001$ (one-way ANOVA, Bonferroni multiple comparison test).

Lack of $\gamma-\mathrm{H} 2 \mathrm{AX}$ in oocytes after DOX and ETO treatments suggests that DSBs are not the predominate type of damage activating CHEK2 signaling leading to oocyte apoptosis.

Taken together we show that CDDP and MAFO induce lethal DSBs in oocytes. Repair of these DSBs is initiated by high fidelity HR but cannot be completed due to activation of proapoptotic response coordinated by CHEK2. Moreover, our results confirm previous reports that topoisomerase II poisons such as DOX and ETO do not induce DSBs in oocytes (57), but rather in ovarian 
somatic cells that are actively proliferating. Nevertheless, primordial oocyte elimination is still observed in CHEK2proficient ovaries, indicating that DOX and ETO affect primordial oocyte survival by a different mechanism. Taken together our results indicate that inhibition of CHEK2 activity in the chemotherapy-treated ovary prevents elimination of primordial oocytes with and without DNA DSBs by providing more time for DNA repair and oocyte survival.

A

A

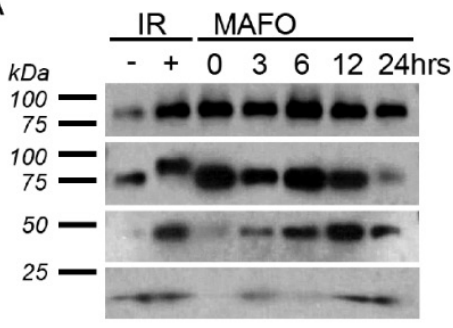

B

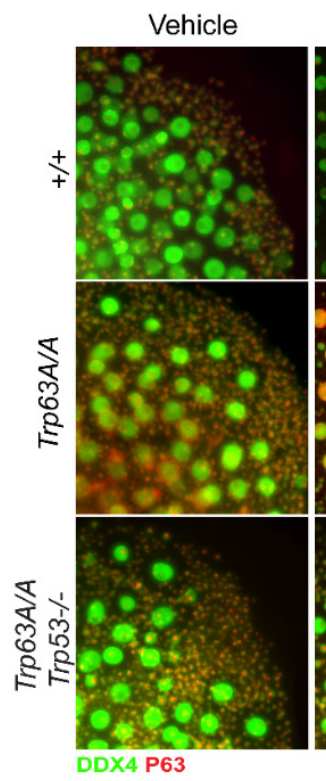

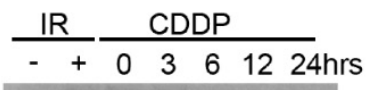

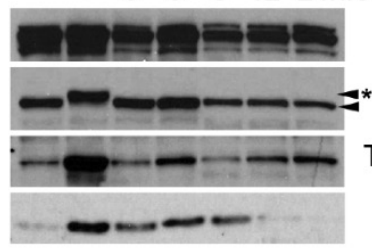

MAFO
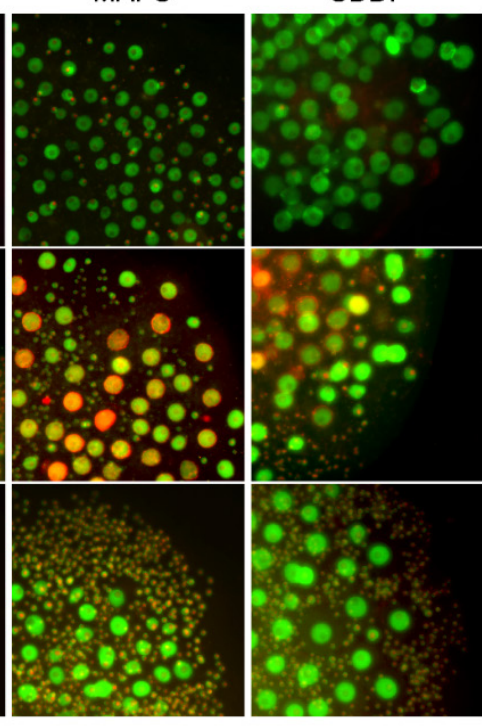

DDX4

*TAp63

TRP53

$\gamma \mathrm{H} 2 \mathrm{AX}$

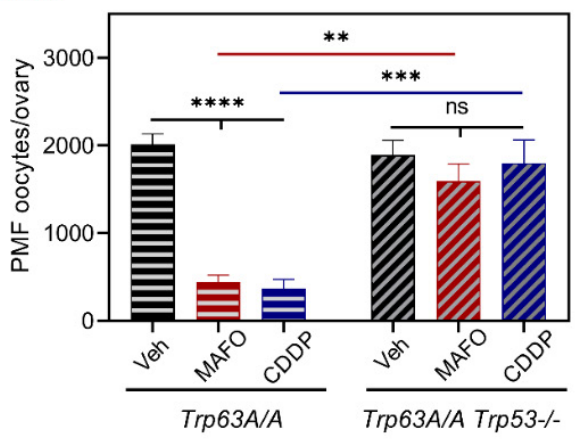

Damage induced by CDDP and MAFO does not induce hyperphosphorylation of TAp63, but triggers activation of TRP53-dependent apoptosis.

In response to radiation-induced damage, CHEK2 phosphorylates two proapoptotic factors; TAp63 specifically in oocytes and TRP53 in all cell types $(26,32,58)$. Unlike TRP53, which requires phosphorylation to avoid degradation, TAp63 is constitutively expressed in oocytes and maintained in an inactive form until phosphorylated $(32,58,59)$. In response to radiation, TAp63 is phosphorylated by CHEK2 and Casein Kinase 1 delta (CK1 $\delta$ ) leading to a mobility shift visible by western blot. In the absence of CHEK2, TAp63 remains unphosphorylated and inactive (26) (Fig. 4A and Fig. S2C). Previous reports suggest that inactivation of TAp63 is sufficient to protect oocytes from CDDP but not CTX induced damage $(33,34)$. Since MAFO and CDDP induce DSBs and trigger CHEK2dependent apoptosis, phosphorylation and activation of TAp63 is expected. However, TAp63 shift was absent after 24 hours of MAFO or CDDP treatment, even though activated TRP53 and $\gamma \mathrm{H} 2 \mathrm{AX}$ were detected by western blot (Fig. 4A). These results suggest that damage induced by MAFO $(2.4 \mu \mathrm{M})$ and CDDP $(1.6 \mu \mathrm{M})$ does not lead to the rapid phosphorylation of TAp63 observed after radiation-induced damage. However, TAp63 phosphorylation has been reported in oocytes after treatments with a higher dose of CDDP $(10 \mu \mathrm{M})(32)$ or after CTX treatment in vivo (53). Therefore, it is possible that DNA damage caused by alkylating agents triggers activation of TAp63 with different dynamics or by a different mechanism. To determine whether TAp63 is involved in MAFO- and CDDP-induced primordial oocyte elimination downstream of CHEK2, we utilized a mouse model with a mutation in the Trp63 gene (Fig. S2A). Here, serine 621 was replaced with alanine (S582 in human) at the TAp63 C-terminus, which was previously showed to be phosphorylated by CHEK2 $(26,32)$. This mutation prevents activation by CHEK2 but does not affect TAp63 expression (Fig. S2C) and results in increased resistance of oocytes to low dose of radiation (0.5Gy) (Fig. S2B). TAp63A/A ovaries were exposed ex vivo to MAFO and CDDP at the same doses and regimen as wildtype and Chek2-/- ovaries (Fig. 4B, C and Fig. 1). Primordial oocyte numbers were reduced in treated

Figure 4. Inhibition of TAp63 phosphorylation by CHEK2 is not sufficient to prevent complete primordial oocyte elimination in response to MAFO and CDDP treatments indicating a role for TRP53. (A) Protein extracts were collected from MAFO and CDDP-treated ovaries at different time points and analyzed by western blot (MAFO at $1 \mu \mathrm{g} / \mathrm{ml}$ at $\mathrm{CDDP}$ at $0.5 \mu \mathrm{g} / \mathrm{ml}$ ). TAp63 phosphorylation leads to mobility shift observed $6 \mathrm{hrs}$ after radiation (IR 0.5Gy). In contrast no shift is observed in CDDP and MAFO treated ovaries up to $24 \mathrm{hrs}$ post treatment. Increased levels of TRP53, indicative of its phosphorylation and stabilization, are observed as early as 3 hrs post drug treatments. DDX4 is an oocyte marker and $\gamma \mathrm{H} 2 \mathrm{AX}$ is a DNA damage marker. (B) Primordial oocytes expressing TAp63 carrying a mutation at its CHEK2 phosphorylation site $(\operatorname{Trp} 63 A / A)$ are not fully resistant to MAFO and CDDP toxicity while double mutant Trp63A/A Trp53-/- oocytes lacking both CHEK2 phosphorylation targets show high resistance and almost normal survival. (C) Primordial (PMF) oocytes were counted in ovaries harvested after 7-day organ culture. Data are expressed as mean $\pm \mathrm{SEM}$; **** $<0.0001$ (one-way ANOVA, Kruskal-Wallis for nonparametric data). 
TAp63A/A ovaries and when compared to Chek2-/-: only $\sim 21.9 \%$ survived (vs. $\sim 107.3 \% \mathrm{P}<0.0001$ ) after MAFO and $\sim 12.7 \%$ (vs. $\sim 83.3 \% \mathrm{P}<0.0001$ ) after CDDP. The reduced number of surviving primordial oocytes in TAp63A/A mutants suggests that other CHEK2 targets contribute to primordial oocyte elimination after CDDPand MAFO-induced damage. CHEK2 is known to phosphorylate TRP53 in response to DNA DSBs, and TRP53 expression was detected in ovaries treated with radiation, MAFO, and CDDP (Fig. 4A). Interestingly, TRP53 was still detected by western blot in irradiated ovaries in Chek2-/- mice, although at lower levels than in the wildtype (Fig. S2C), indicating that CHEK1 or other kinases can still activate TRP53 in the absence of CHEK2. However, it remains unclear whether the remaining TRP53 is activated in oocytes or ovarian somatic cells. To test if TRP53 contributes to primordial oocyte elimination after MAFO and CDDP-induced damage, oocyte survival was tested in double mutant ovaries lacking activity of both TAp63 and TRP53. Compared to $\operatorname{Trp} 63 A / A$ single mutant, primordial oocyte
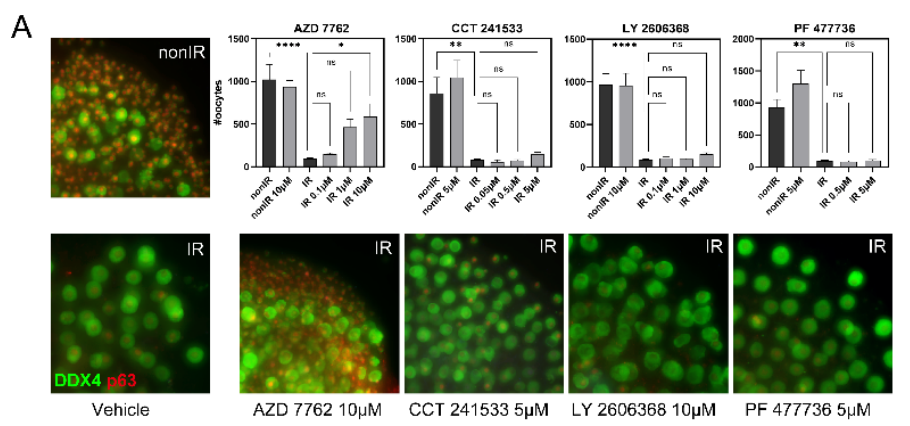

B

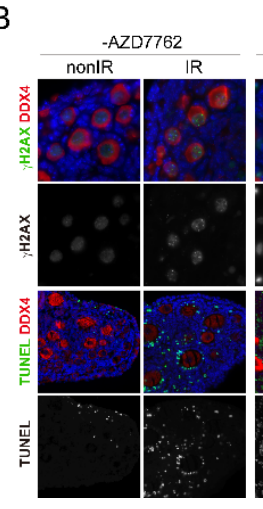

AZD $776210 \mu \mathrm{M}$

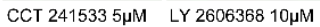

C
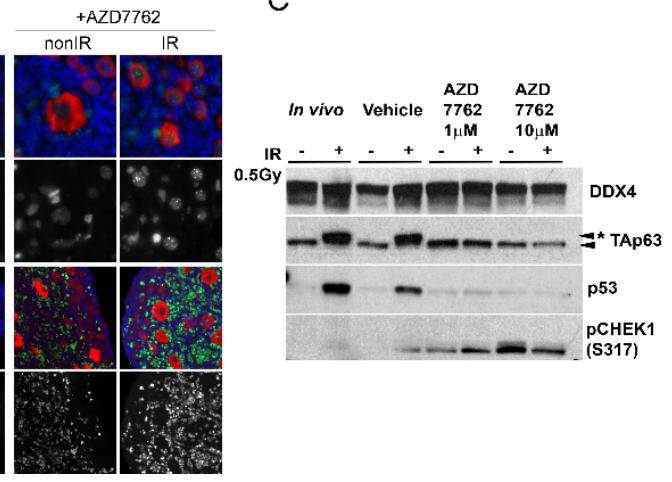

survival was significantly improved in $\operatorname{Trp} 63 \mathrm{~A} / \mathrm{A} \operatorname{Trp} 53$ / double mutant ovaries $(21.9 \%$ vs. $84.4 \% \mathrm{P}=0.002$ after MAFO and $12.7 \%$ vs. $99.4 \% \mathrm{P}=0.0013$ after CDDP) (Fig. 4C). This confirms that TRP53 is activated in the ovaries after MAFO and CDDP-induced damage and that it contributes to primordial oocyte elimination. Because CHEK2 is expressed in all ovarian cells, further studies are required to determine if TRP53 activity, critical to primordial oocyte elimination, comes from surrounding ovarian somatic cells or the oocyte itself. Taken together, genetic analysis reveals the critical role for CHEK2 in coordinating PMF loss after MAFO and CDDP-induced damage by activating two proapoptotic factors TAp63 and TRP53.

\section{Transient pharmacological inhibition of CHEK2 improves primordial oocyte survival after CDDP and MAFO treatment.}

Genetic ablation of CHEK2 activity prevents depletion of PMF reserve in mice treated with chemotherapy drugs (this study) and radiation (26). Moreover, pharmacological inhibition with CHEK2 Inhibitor II (BML-277) reduced oocyte loss after radiation and resulted in healthy offspring from surviving oocytes (36). Because of similarities between CHEK1 and CHEK2, most available inhibitors block the activity of both kinases, although with different affinities. CHEK1 is an essential kinase which coordinates DDR and cell cycle progression in all dividing cells (60). CHEK $1 / 2$ inhibitors have been shown to potentiate the effects of genotoxic chemotherapy drugs against cancer (61-65) and some are being tested in clinical trials. Therefore, inhibitors blocking CHEK2 and CHEK1 could have the added benefit of improved cancer cell elimination in addition to oocyte protection. To test the ability of other CHEK $1 / 2$ inhibitors to prevent oocyte depletion following radiation and chemotherapy treatments, four inhibitors shown or predicted to target CHEK2 were tested; AZD7762 (IC50 CHEK2 10nM and CHEK1 5nM), CCT241533 (IC50 CHEK2 3nM and CHEK1 245nM), LY2606368 (IC50 CHEK2 8nM and CHEK1 $<1 \mathrm{nM}$ ), and PF477736 (IC50 CHEK2 $47 \mathrm{nM}(\mathrm{Ki})$ and CHEK1 $0.49 \mathrm{nM}(\mathrm{Ki})$; IC50 provided by suppliers). The pharmacokinetics of these

Figure 5. CHEK1/2 inhibitor AZD7762 reduces primordial oocyte loss in prepubertal ovaries after radiation (IR) but exhibits cytotoxic effects in proliferating somatic cells. (A) Ovaries were treated with CHEK2 inhibitors ex vivo for 2 hrs prior to IR and for $24 \mathrm{hrs}$ post IR. After $24 \mathrm{hrs}$ inhibitors were withdrawn and ovaries cultured for 6 days. AZD7762 but not CCT241533, LY2606368 or PF477736 showed protection of PMF oocytes after 7-day culture. Graphs show numbers of oocytes per ovary present after treatment with increasing doses of inhibitors. Data are expressed as mean $\pm \mathrm{SEM} ; * \mathrm{p}<0.05, * * \mathrm{p}<0.01, * * * \mathrm{p}<0.001$, $* * * * \mathrm{p}<0.0001$ (one-way ANOVA, Kruskal-Wallis with Dunn's multiple comparison test for nonparametric data). Below, panels show examples of treated ovaries immunostained with oocyte markers DDX4 and p63. (B) AZD7762 treatment causes increased levels of $\gamma \mathrm{H} 2 \mathrm{AX}$ (green) staining in the absence of IR. TUNEL staining (green) for apoptotic cells shows increased apoptosis in samples treated with AZD7762. Oocyte marker DDX4 (red). (C) Ovarian protein extracts were collected 6 hrs after IR with 0.5Gy with and without AZD7762 treatment and were analyzed by western blot. TAp63 mobility shift (asterisk) indicative of phosphorylation and p53 expression are not detected in inhibitor treated ovaries. Increased levels of pCHEK1(S317) are present only in AZD7762 treated ovaries. 
inhibitors in mouse are unknown. Therefore, we used our ex vivo ovary culture system to better control the timing and dosing of drugs and inhibitors without the confounding influence of transport and metabolism found in vivo. First, ovaries were treated with increasing doses of inhibitors in combination with ionizing radiation $(0.5$ Gy) (Fig. 5A). Ovaries were cultured with inhibitors for 2 hours prior to treatment to assure cellular presence of the inhibitor before DNA damage is induced and for additional 48 hours after radiation. Oocyte numbers were counted in immunostained whole ovaries after an additional 5 days of culture without any inhibitors to ensure quantification of oocyte survival and not a delay in apoptosis. Treatment with CCT241533 $(0.05,0.5$ and $5 \mu \mathrm{M}), \mathrm{LY} 2606368(0.1,1$ and $10 \mu \mathrm{M})$, and PF477736 $(0.5,5$ and $50 \mu \mathrm{M})$ had no significant impact on primordial oocyte survival after radiation at any dose tested (Fig. 5A) indicating failure to sufficiently block CHEK2 activity in oocytes. AZD7762 treatment improved primordial oocyte survival compared to vehicle-treated irradiated ovaries (Fig. 5A). We calculated survival as a percentage of oocyte reserve in non-irradiated ovaries. Survival was estimated at $57.3 \%$ after $10 \mu \mathrm{M}$ AZD7762 ( $\mathrm{P}=0.001)$ vs.
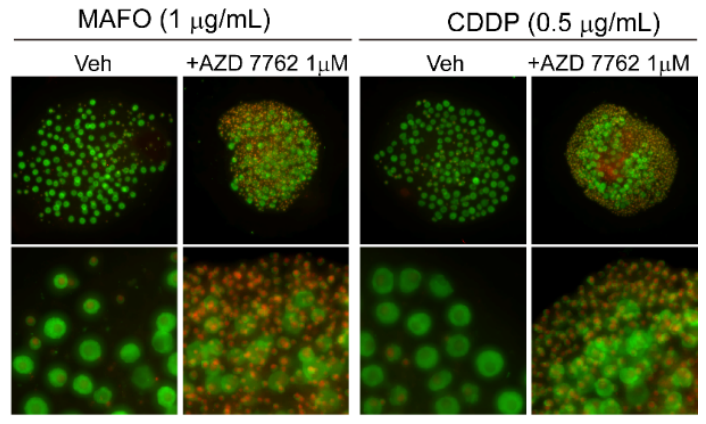

DDX4 p63

B

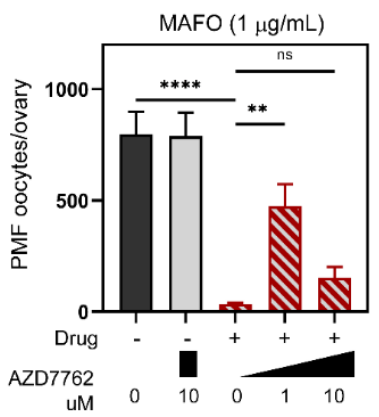

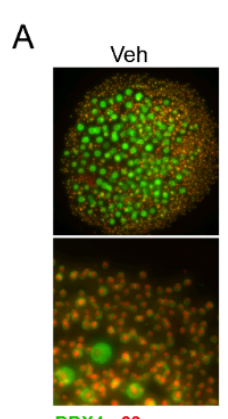

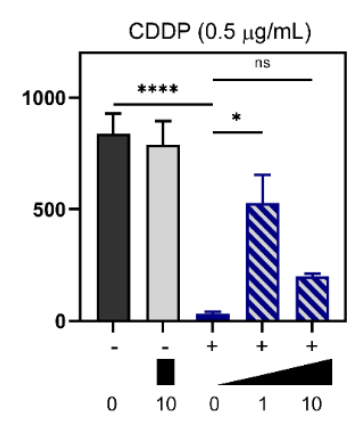

Figure 6. Co-treatment with AZD7762 reduces primordial oocyte loss in prepubertal ovaries after treatment with chemotherapy drugs. (A) Example ovaries co-treated with AZD7762 and MAFO or CDDP in ex vivo organ culture. AZD7762 showed protective effect and presence of primordial oocytes after 7-day culture. Oocyte markers DDX4 (green) and p63 (red). (B) Graphs show numbers of primordial oocytes per ovary present after co-treatment with increasing doses of AZD7762 inhibitor. Data are expressed as mean $\pm \mathrm{SEM} ;{ }^{*} \mathrm{p}<0.05,{ }^{*} \mathrm{p}<0.01$, $* * * \mathrm{p}<0.001, * * * * \mathrm{p}<0.0001$ (one-way ANOVA, KruskalWallis with Dunn's multiple comparison test for nonparametric data).
$10.1 \%$ with vehicle. Survival at lower doses of inhibitor $(0.1$ and $1 \mu \mathrm{M})$ was improved but more variable. Despite increased primordial oocyte survival, ovarian explant growth was impaired in AZD7762 treated ovaries. Immunostaining for DNA damage marker $\gamma \mathrm{H} 2 \mathrm{AX}$ and TUNEL for apoptosis shows that AZD7762 treatment alone causes accumulation of DNA damage and increased apoptosis in ovarian somatic cells which was further enhanced by radiation (Fig. 5B). Since Chek2-/- ovaries show normal growth after radiation, these results suggest that AZD7762 inhibited CHEK1 kinase which interfered with cell cycle progression in proliferating stromal and granulosa cells. This led to accumulation of DNA damage and triggered apoptosis in somatic cells but not in oocytes.

To validate that AZD7762 prevents primordial oocyte death by inhibition of CHEK2-dependent signaling, we performed western blots of TAp63 and TRP53 as before $(66,67)$. TAp63 was phosphorylated after radiation which resulted in the expected mobility shift and TRP53 was readily detected (Fig. 5C). In ovaries treated with AZD7762, TAp63 remained unphosphorylated and TRP53 was reduced which confirms that AZD7762 efficiently inhibited CHEK2 activity in oocytes and prevented TAp63-activation. CHEK1 is phosphorylated on Serine 317 by ATR kinase in response to DNA damage (60), which we were able to detect in all AZD7762-treated cells (Fig. 5B). To test whether AZD7762 could also protect primordial oocytes against chemotherapy drugs, ovaries were co-treated with AZD7762 $(1 \mu \mathrm{M}$ and $10 \mu \mathrm{M})$ and MAFO or CDDP (Fig. 6A, B). Oocyte survival was calculated as a percentage of ovarian reserve in untreated ovaries. Oocyte survival increased in $1 \mu \mathrm{M}$ AZD7762treated ovaries compared to vehicle control following cotreatment with MAFO (59.6 vs. $4.5 \% \mathrm{P}=0.0003)$ and CDDP (63.1 vs. 3.9\% $\mathrm{P}=0.0006$ ). Despite improved oocyte survival, retardation of ovarian growth was also observed in co-treatment with chemotherapy drugs (Fig. 6A). This suggests that despite its ovoprotective and cancer sensitizing properties, AZD7762 causes additional cytotoxic side effects in the ovary. AZD7762 cardiotoxicity was reported in clinical trials which led to their termination (68-72). In summary, these data show that transient inhibition of CHEK2 is a feasible approach to protect ovarian PMF reserve during genotoxic chemotherapy treatments providing that a highly specific CHEK2 inhibitor is used.

\section{DISCUSSION}

Genotoxic cancer treatments can damage and diminish PMF reserve in cancer patients causing POI and fertility problems, posing challenges that reveal the limitations of our understanding of the basic biology of oocyte in the context of follicle environment. Mouse studies demonstrate that PMF loss can be prevented in females 
treated with genotoxic agents, and that these mice remain fertile and produce healthy pups. However, it remains unclear what might be the safest and most effective way to mitigate PMF loss in female cancer patients. In this study, we show that CHEK2 kinase is responsible for coordinating elimination of primordial oocytes after damage with several chemotherapy drugs, making it an attractive target for the development of ovoprotective treatments. Genetic ablation of CHEK 2 protected $>90 \%$ of PMF reserve in females treated with two very ovotoxic drugs, CTX and CDDP, demonstrating that blocking CHEK2 is sufficient to protect PMF reserve in mice. Although fertility was not assessed in this study, evidence from prior work and other studies indicate that primordial oocytes that survive genotoxic insults do indeed support normal ovarian function and fertility $(26,33,35,36)$. Moreover, CHEK2 inactivation also almost completely protected primordial oocytes from MAFO, DOX and ETO toxicity in ex vivo organ culture system. Although DOX and ETO are not as ovotoxic as alkylating agents in human $(38,73,74)$, they are used in many combination therapies (75-77). Thus, these findings suggest the protective effect of CHEK2 inhibition is likely to be beneficial for a broad spectrum of patient treatments. Further, we demonstrate that a CHEK1/2 inhibitor previously shown to sensitize cancer cells to chemotherapy significantly improved primordial oocyte survival after either radiation or treatment with alkylating agents. Finally, our genetic dissection of the signaling mechanisms responsible for PMF elimination post genotoxic insult establishes CHEK2 as a master regulator of this process and reveals parallel and redundant downstream pathways that involve both TAp63 and TRP53.

How different chemotherapy drugs inflict damage in ovaries and oocytes specifically, and how this damage triggers primordial but not growing oocyte elimination is still not fully understood. Chemotherapy drugs can damage DNA directly and indirectly by increasing oxidative stress. Moreover, oxidative stress causes other cellular damage via protein and lipid peroxidation, which can also lead to cell death (78). Here, we show that alkylating agents such as CDDP, MAFO, and CTX induce abundant DNA DSBs (as previously reported $(49,79)$ ) in oocytes that in turn trigger CHEK2 activation and subsequent loss of PMFs by oocyte apoptosis. In contrast, we did not detect a significant increase in DSB markers in primordial oocytes after DOX or ETO treatment, suggesting a different mode of toxicity for these agents. It is possible that DOX induces late DNA damage in oocytes indirectly by increasing oxidative stress and reactive oxygen species (ROS) (80-83). Indeed, co-administration of drugs reducing oxidative stress have been shown to decrease its ovotoxicity (84-86) and $\gamma \mathrm{H} 2 \mathrm{AX}$-positive oocytes were reported after in vivo treatment with DOX
$(57,87)$. The improved survival of primordial oocytes in Chek2-/- ovaries after DOX and ETO exposure suggests that these drugs induce CHEK2 signaling independently of nuclear DNA damage, most likely through increased oxidative stress $(81,88-91)$. Studies show that DOX and ETO treatment are most damaging to actively proliferating granulosa cells $(38,40,41,57)$. It remains unclear whether loss of PMFs after DOX and ETO is driven by the response from the oocyte or surrounding granulosa cells and if damage to one cell type is communicated to the other within the follicle (discussed below). Because CHEK2 is expressed in all cells in the ovary, its inactivation in oocytes, granulosa cells or both may be responsible for observed primordial oocyte survival.

The primordial oocyte response to DNA DSBs induced by radiation involves CHEK2 and its downstream target TAp63, with TRP53 shown to be dispensable $(26,92,93)$. Both genetic and biochemical evidence indicate that phosphorylation by CHEK2, followed by $\mathrm{CK} 1 \delta$, are needed to fully activate TAp63 (26,32). Hyperphosphorylated TAp63 can then tetramerize and function as a transcription factor $(32,58,59,94)$. However, the role of CHEK2 in the response to alkylating agents has been unclear due to discrepancies in TAp63 hyperphosphorylation status and its requirement for oocyte elimination. TAp63 hyper-phosphorylation is not evident after CDDP and MAFO treatments (this study and $(34,95))$ but has been reported after in vivo administration of CTX (53), whereas TAp63 null oocytes are resistant to CDDP but not to CTX $(33,34)$. A study using an array of DDR inhibitors against ATR, ATM, CHEK1 and CHEK2 kinases suggested that radiation and CDDP activate TAp63 by two distinct signaling cascades; $\mathrm{ATM} \rightarrow \mathrm{CHEK} 2 \rightarrow$ TAp63 and ATR $\rightarrow$ CHEK1 $\rightarrow$ TAp63, respectively (34). Since many DDR inhibitors show activity towards other kinases $(96,97)$ and there is a crosstalk between ATM and ATR pathways (98-100) it is possible that survival attributed to ATR $\rightarrow$ CHEK1 inhibition is due to off-target inhibition of CHEK2. In this study, we observed that the inhibitor AZD7762 targeted both CHEK1 and CHEK2 kinases while other predicted CHEK2 inhibitors failed to inactivate CHEK2 and showed no protective effects. While inhibitor studies are helpful in initial identification of signaling cascades involved in cellular responses, genetic studies are necessary to determine precise mechanistic roles for individual proteins (97), for example, as shown for imatinib and ABL1 kinase. Initial studies with the inhibitor imatinib provided conflicting results about its protective effects against CDDP while genetic study demonstrated that ABL1 kinase is dispensable for elimination of CDDP-damaged oocytes $(40,95,101-103)$. Here, using a genetic approach we demonstrate that CHEK2 is directly responsible for elimination of 
primordial oocytes damaged by both CDDP and CTX and that CHEK1 activity does not significantly contribute to oocyte elimination even in the absence of CHEK2.

Since previous reports suggested TAp63-/- oocytes are resistant to CDDP but not to CTX $(33,34)$, and that Chek2-/- oocytes are resistant to both (this study), other types of cellular damage and/or other targets of CHEK2 must be involved in signaling pathways leading to elimination of oocytes damaged by CTX. At least two putative mechanisms underlying its ovotoxic effect have been proposed: 1) accelerated activation of PMFs causing so called follicle "burn-out" via the PTEN/AKT/FOXO3a pathway $(44-46,50)$; and 2) direct damage to the oocyte triggering apoptosis via the DDR pathway $(35,48,49)$. However, the relative contribution of these two mechanisms to PMF loss remains controversial $(35,44$ $46,48,104,105)$. CTX treatment in pre- and post-pubertal mice demonstrated that primordial oocytes are lost within 3 days without an increase in the number of growing follicles, indicating that follicle burn-out is not the major mechanism regardless of female age (35). This study and others show that CTX and its derivative MAFO are potent

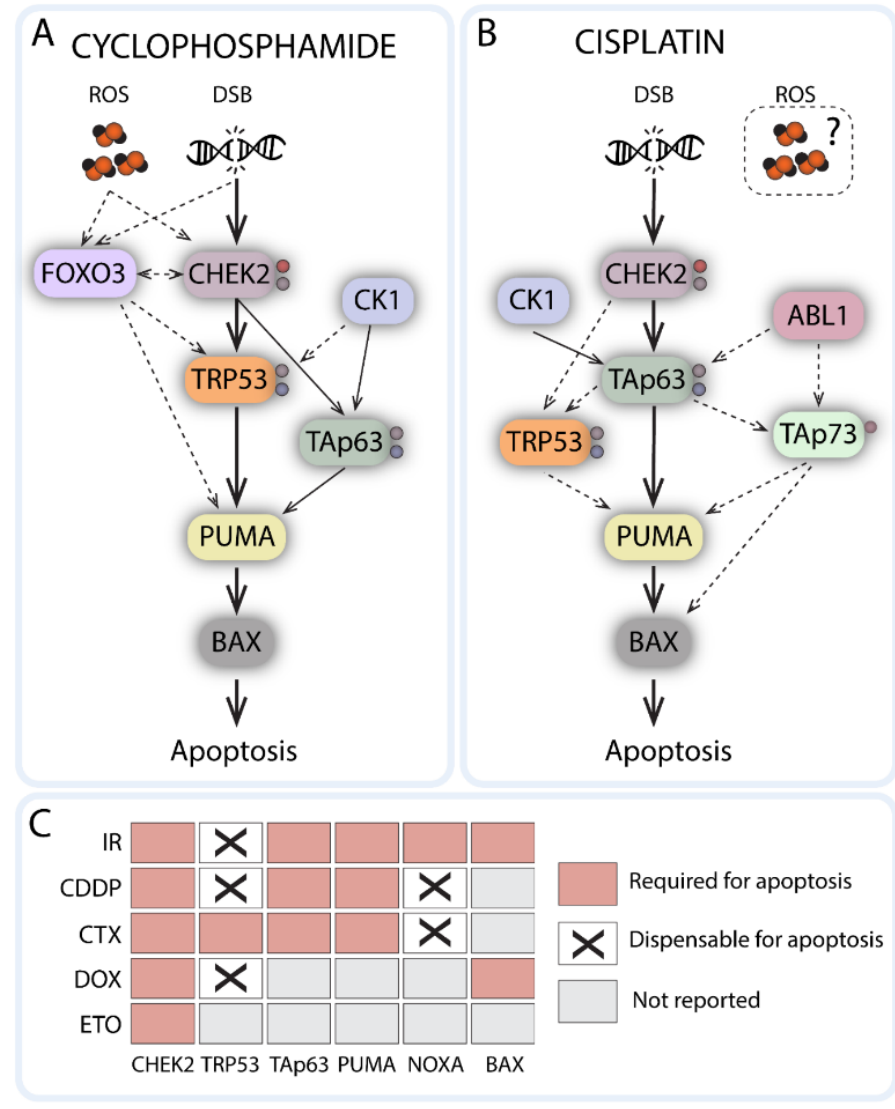

inducers of DSBs and apoptosis in oocytes $(49,106)$.
Therefore, primordial oocyte survival in ovaries lacking CHEK2 - the essential DSB response kinase - after both MAFO (ex vivo) and CTX (in vivo) treatments strongly suggests that DNA damage is the major mechanism underlying primordial oocyte loss after CTX treatment. Even though radiation, CDDP, and MAFO/CTX all induce DSBs in oocytes, the mechanisms for the ensuing activation of TAp63 and TRP53 are different. We show that despite inducing slightly lower levels of DSBs than CDDP, MAFO treatment specifically activates TRP53dependent apoptosis suggesting that DSB-independent cellular damage induces TRP53. Full survival of primordial oocytes in MAFO treated ovaries was achieved only after both TRP53 and TAp63 were deleted, suggesting that MAFO-induced damage activates both targets of CHEK2 independently or that they can substitute for each other. Oxidative stress could play a role as CTX and its derivatives produce reactive metabolites such as phosphoramide mustard and acrolein that cause overproduction of ROS which is known to activate CHEK $2 \rightarrow$ TRP53 pathway $(37,88,89,107,108)$. CDDP and radiation also induce oxidative stress (109111), yet they do not activate TRP53-dependent primordial oocyte loss even in the absence of TAp63 $(33,34)$. In contrast to oocyte-specific expression of TAp63, TRP53 is ubiquitously expressed in the ovary as is CHEK2. Therefore, damage to granulosa cells in the PMF or other cell types in the ovary could potentially trigger oocyte loss through intercellular signaling independent of TAp63 activity in the oocyte, which is prevented by CHEK 2 or TRP53 inactivation.

Surprisingly, in contrast to TAp63-/- null genetic model, we observed that primordial oocytes expressing the phosphomutant TAp63A/A - lacking CHEK2 phosphorylation site associated with hyperphosphorylation - were still largely sensitive to CDDP even though CHEK2-deficient oocytes were fully resistant to the same dose. This difference in oocyte survival in the mutants raises two intriguing possibilities; 1) another modification downstream of CHEK2 contributes to TAp63 activation without inducing a hyper-phosphorylated state (as alluded by (34)) or 2) other proapoptotic proteins regulated by CHEK2 are involved. Because TAp63 substitutes for TRP53 function during elimination of oocytes with unrepaired meiotic DSBs (26), we favor the latter explanation. Indeed, we show that deleting Trp53 in TAp63 phosphomutant background results in CDDP resistance, indicating that TRP53 can contribute to elimination of CDDP-damaged primordial oocytes; however it remains unclear how. It is

Figure 7. Schematic model of DNA damage signaling in primordial oocytes after cyclophosphamide (CTX) and cisplatin (CDDP) exposure. Solid arrows indicate validated interactions, dashed arrows indicate proposed interactions. DSB: Double Strand Breaks; ROS: Reactive Oxygen Species. C) Matrix illustrating the role of individual proteins in oocyte apoptosis in response to IR and chemotherapy drugs revealed by mutant phenotypes. DOX: Doxorubicin, ETO: Etoposide 
possible that TAp63 phosphomutant protein triggers oocyte apoptosis by forming an active heterotetramer with TRP53. Although heterotypic interactions have not been detected between wildtype TRP53 and TAp63 in somatic cells (112-114), further investigations are needed to exclude this possibility in oocytes.

Phenotypic analyses of selective mouse mutants reveal a complex network of signaling, with responses depending on the type of drug and potentially type of the cellular damage (Fig. 7A, B). Chek2-/- oocytes survive radiation, CDDP, CTX, DOX, and ETO treatments. Downstream of CHEK2, TRP53 is involved in elimination of oocytes exposed to CTX but not CDDP or radiation, while TAp63 seems to be solely responsible for elimination of oocytes exposed to low dose radiation and CDDP (Fig. 7C). TRP53 and TAp63 are known to induce expression of multiple target genes involved in apoptosis, including Bbc3 (Puma) and Pmaipl (Noxa) (25,115-117). Oocytes lacking PUMA are fully resistant to CTX and CDDP (33), but only moderately resistant to radiation (25). To fully protect oocytes from radiation-induced damage, both PUMA and NOXA need to be inactivated (25). FOXO3a has been suggested to directly activate Puma expression in CTX-treated ovaries, thus explaining TAp63independent oocyte apoptosis $(33,118-120)$. Importantly, FOXO3a was shown to be essential for DNA damageinduced apoptosis dependent on ATM, CHEK2 and TRP53 activity in somatic cells $(121,122)$. Therefore, it is plausible that CTX/MAFO induced damage activates TRP53 via FOXO3a $\rightarrow$ CHEK2 signaling. FOXO3a is also involved in cellular response to oxidative stress (123-125) thus increased production of ROS in CTXtreated cells can lead to activation of FOXO3a $\rightarrow$ TRP53 $\rightarrow$ PUMA signaling (Fig. 7A). While these differences in downstream signaling likely reflect nuances in types and/or levels of cellular damage induced by various chemotherapies, CHEK 2 nonetheless emerges as a master regulator of primordial oocyte survival or death after exposure to all tested genotoxic agents.

In contrast to oocyte specific activity of TAp63, CHEK2 and TRP53 are both also expressed in ovarian cells and thus expected to be involved in DDR response in the granulosa cells as well as in oocytes. Within the follicles, the oocyte and granulosa cells are connected by gap junctions facilitating the bidirectional communication between them (126). These connections ensure exchange of critical metabolites and signaling molecules that support follicular development and survival of both the oocyte and granulosa cells (127-129). While understanding of the molecular mechanisms of radiation and chemotherapy-induced oocyte loss has increased in recent years, the role of intercellular germ cell-soma communication is still emerging. The "bystander effect" where non-targeted cells are affected by adjacent damaged cells has been described for radiation and chemotherapy drugs (130-133), therefore it is possible that granulosa cells with cellular damage affect primordial oocyte survival and vice versa through bidirectional communication pathways. Interestingly, gap junctions have been reported to relay DNA damage response to radiation and cisplatin between neighboring cells (134-136) involving ATM, TRP53 and ROS signaling (137-141). Although, it is unclear if crosscommunication of DNA damage takes place within the PMF, it has been reported for cumulus-cell enclosed oocytes (142). Further studies, both of clinical responses to chemotherapy and the basic biology of intra-follicle cell communication are required to fully resolve the mechanisms of chemotherapy induced cellular damage and how or where it activates the CHEK2 and TRP53dependent response.

DNA damage inflicted in oocytes, either directly or indirectly, seems to be the major trigger of PMF elimination and resulting POI after radiation and chemotherapy; therefore, blocking the DDR signaling responsible for this elimination is a promising strategy to prevent POI. Mouse genetic studies have revealed very few targets in the DDR pathway that prevent or minimize elimination of primordial oocytes. Inactivation of proapoptotic factors PUMA and NOXA effectively protected primordial oocytes from radiation and chemotherapy induced damage $(25,33,49)$. However, blocking apoptosis directly may pose an issue for cancer treatment and development of resistance to therapy (143). Inhibition of TAp63 and TRP53, protects primordial oocytes from low dose radiation and selected chemotherapies $(25,33,92,93)$ but targeting transcription factors remains challenging and there are currently no specific inhibitors for TAp63 (144). Consequently, inhibition of DDR kinases responsible for triggering oocyte elimination may be the best approach. CHEK2 and CK1 $\delta$ are needed for activation of TAp63 in response to DSBs and are both also involved in regulation of TRP53 $(67,145-147)$. Inhibition of their activity genetically or pharmacologically protects primordial oocytes from radiation and selected chemotherapies $(26,32)$. There are six members of the casein kinase family involved in diverse cellular processes including tumorigenesis (148$150)$ therefore CK1 $\delta$ specific inhibitors (151) would need to be developed to avoid off-target effects. Using mouse models and CHEK2 inhibitors, we show here that specific inhibition of CHEK2 could be an effective method to prevent chemotherapy-induced loss of ovarian follicle reserve. Moreover, specific inhibition of CHEK2 may also improve cancer treatment outcomes, as DDR kinase inhibitors can sensitize cancer cells to chemotherapy (152). Chek2-/- mice are viable, fertile, and do not develop tumors. This suggests that transient inhibition of CHEK2 would be a safe strategy $(66,147)$. While 
germline mutations in CHEK2 have been found in patients with breast, colon, and prostate cancers, these appear insufficient to drive cancer progression in the absence of the other cancer susceptibility genes (153). Clinical interpretation of germline CHEK2 variants is variable, as studies reported their association with increased, decreased, or no risk in various cancers (153). Therefore, further studies are needed to assess the efficacy and safety of transient CHEK2 inhibition in animal models with genetic predisposition to cancer. Comparative analyses of the prevalence of POI in female cancer patients carrying deleterious mutations in CHEK2 vs. control cohort may also provide insight into the role of CHEK2 in human oocytes' sensitivity to genotoxic agents and relevance to chemotherapy induced POI as a predictive marker. Recent GWAS studies identified CHEK2 as a major factor associated with ovarian aging and the onset of natural menopause in women $(154,155)$. Animal model studies showed that this is due to a larger PMF reserve found in CHEK2-deficient mice $(26,155,156)$. Furthermore, we showed that CHEK2deficient primordial oocytes are more resistant to DNA damage induced by radiation (26) and chemotherapy drugs (this study), and we expect that they will be resistant to other types of DNA damaging exposures. Thus, better understanding of how oocytes respond to DNA or other types of cellular damage will contribute to our knowledge of ovarian aging and the maintenance of follicle reserve in women during lifetime exposure to various factors.

\section{Acknowledgments}

This study was supported in part by grant from the $\mathrm{V}$ Foundation for Cancer Research to EBF (V Scholar Award V2017-019). The authors would like to thank R. Munroe and C. Abratte of Cornell's Transgenic Facility for generating the edited mice (supported by a contract CO29155 from the NY State Stem Cell Program (NYSTEM) and R01 GM45415).

\section{MATERIALS AND METHODS}

\section{Animals}

All procedures used in this study were approved by the IACUC at The Jackson Laboratory. C57BL/6J (JAX stock\#000664), $\quad \operatorname{Tg}($ Pou5f1-EGFP)2Mnn/J (JAX stock\#004654) and Trp53 $3^{\text {tmlTyj/J }}$ (JAX stock\#002101) were obtained from The Jackson Laboratory. Chek2 $2^{\text {tmIb(EUCOMM)Hmgu }}$ mice were obtained from KOMP program at JAX. Trp $63^{\mathrm{S} 621 \mathrm{~A}}$ mutant line was generated using CRISPR/Cas9 mediated genome editing as described in Fig. S2. For radiation experiments, 7-day-old females were irradiated using a Cesium-137 gamma irradiator. They were exposed to a total dose of $0.5 \mathrm{~Gy}$ or $3 \mathrm{~Gy}$ administered at a rate of $(170 \mathrm{Rad} / \mathrm{min})$. Ovaries were collected for protein extracts for western blot analysis or fixed in 4\% PFA for immunostaining. For chemotherapy drug treatments, 7-day-old females received a single i.p. injection of saline, CDDP (5 mg/kg) (Millipore Sigma) or CTX $(150 \mathrm{mg} / \mathrm{kg}$ ) (Millipore Sigma). Doses were chosen based on previously published studies $(49,50)$. Mice weights were recorded one and two weeks after injection. Ovaries were collected two weeks after injection, fixed in Bouin's solution for histological analyses.

\section{Follicle quantification}

Bouin's fixed ovaries were embedded in paraffin and cut into $5 \mu \mathrm{m}$ serial sections. Sections were stained with Periodic acid-Schiff (PAS) and follicle number was evaluated in every 5th section. Follicle stages were determined using standard methods. Briefly, primordial follicles were surrounded by a layer of squamous pregranulosa cells; primary follicles had a single layer of cuboidal granulosa cells; secondary follicles had more than one granulosa cell layer but lacked antrum; antral follicles had visible antrum. Final follicle count is represented as the sum of follicles in every $5^{\text {th }}$ section multiplied by a correction factor $5(157,158)$. Percentage survival was calculated by dividing the mean of the treatment group counts by the mean of the control group counts and multiplying by a factor of 100 .

\section{Organ culture and drug ex vivo treatments}

Ovaries collected from 7-day-old pups were cultured on polycarbonate membrane (Whatman Nucleopore Polycarbonate membrane) in MEM (Gibco) supplemented with 10\% Fetal Bovine Serum (FBS, Seradigm), $25 \mathrm{mM}$ HEPES (Lonza), and 1X Pen/Strep (Gibco). Ovarian explants were incubated at $37^{\circ} \mathrm{C}, 5 \%$ $\mathrm{CO}_{2}$, and atmospheric $\mathrm{O}_{2}$. Chemotherapy drugs and inhibitors were purchased in powder form and reconstituted following manufacturers recommendations. Cisplatin (CDDP, Selleckchem), mafosfamide (MAFO; CTX-analog, US Biological), doxorubicin (DOX, Selleckchem), and etoposide (ETO, Merck Millipore), and inhibitors AZD7762 (Selleckchem), CCT241533 (TOCRIS), LY2606368 (Selleckchem), and PF477736 (TOCRIS). Stock solutions for all compounds were prepared in DMSO except for CDDP which was dissolved in DMF (as recommended by supplier). DMSO and DMF were used as vehicle controls and their resulting concentration in culture media was less than $0.1 \%$. We used MAFO in ex vivo culture to imitate the in vivo activity of CTX, which needs to be metabolized by the liver to generate metabolites with alkylating properties $(37,42)$. During drug treatments, ovaries were cultured with drugs for 2 days, then cultured in drug-free medium for 5 days before further experimentation (7 days total). 
The culture medium was changed every 2 days. During inhibitor treatments, ovaries were cultured with inhibitors for $2 \mathrm{hrs}$ prior to irradiation or drug treatment. Following radiation $(0.5 \mathrm{~Gy})$, medium was changed to inhibitor-free $\sim 24 \mathrm{hrs}$ after radiation. When ovaries were cultured with drugs, replacement to normal medium (drug and inhibitor-free) occurred at $48 \mathrm{hrs}$ after treatment start. Ovaries were cultured for a total of 7 days for oocyte survival analyses or for 3-24 hrs for protein analyses. Drug and inhibitor concentrations used were as follows: CDDP $0.1 \mu \mathrm{g} / \mathrm{ml}(0.3 \mu \mathrm{M}), 0.25 \mu \mathrm{g} / \mathrm{ml}(0.8 \mu \mathrm{M}), 0.5$ $\mu \mathrm{g} / \mathrm{ml}(1.6 \mu \mathrm{M})$; MAFO $0.1 \mu \mathrm{g} / \mathrm{ml}(0.4 \mu \mathrm{M}), 0.5 \mu \mathrm{g} / \mathrm{ml}$ $(1.2 \mu \mathrm{M}), 1 \mu \mathrm{g} / \mathrm{ml}(2.4 \mu \mathrm{M})$; DOX $25 \mathrm{ng} / \mathrm{ml}(43.1 \mathrm{nM})$, $50 \mathrm{ng} / \mathrm{ml}(86.2 \mathrm{nM}), 100 \mathrm{ng} / \mathrm{ml}(172.5 \mathrm{nM})$; ETO 50 $\mathrm{ng} / \mathrm{ml}(84.5 \mathrm{nM}), 100 \mathrm{ng} / \mathrm{ml}(170 \mathrm{nM}), 500 \mathrm{ng} / \mathrm{ml}(849.5$ $\mathrm{nM})$; AZD7762 (0.1, 1 and $10 \mu \mathrm{M})$, CCT241533 (0.05, 0.5 and $5 \mu \mathrm{M})$, LY2606368 $(0.1,1$ and $10 \mu \mathrm{M})$, and PF477736 (0.5, 5 and $50 \mu \mathrm{M})$.

\section{Immunofluorescence and TUNEL staining}

Slides with $5 \mu \mathrm{m}$ ovarian sections were processed using standard methods. Briefly, sections were deparaffinized and re-dehydrated before antigen retrieval using sodium citrate buffer $(10 \mathrm{mM}$ sodium citrate, $0.05 \%$ Tween 20 , $\mathrm{pH}$ 6.0). Sections were permeabilized in $0.2 \%$ Triton X100 in PBS and blocked with $10 \%$ goat serum for $1 \mathrm{hr}$, before incubation with primary antibodies at $4^{\circ} \mathrm{C}$ overnight. Secondary antibodies were applied for $1 \mathrm{hr}$ and slides were mounted with VectaShield (Vector Laboratories) after Hoechst 33342 (Biotechne) staining. Primary antibodies used in this study were mouse antip63 (4A4, Biocare Medical, CM163A), rabbit anti-DDX4 (Abcam, ab13840), mouse anti- $\gamma \mathrm{H} 2 \mathrm{AX}$ (Millipore, 05636), rabbit anti-RAD51 (Abcam, ab176458), rabbit anti53BP1(Novus NB100-304). Secondary antibodies used were Alexa Fluor (Invitrogen). TUNEL staining for apoptotic cells was performed using DeadEnd Fluorometric system (Promega G3250) according to manufacturer's recommendations.

\section{Whole mount staining of ovaries}

Whole mount immunostaining of cultured ovaries was performed as described in (159). Briefly, explanted ovaries attached to the polycarbonate membrane were fixed in $2 \%$ PFA at $4{ }^{\circ} \mathrm{C}$ overnight. Fixed ovaries were washed with $70 \%$ ethanol overnight and placed in PBS for at least $4 \mathrm{hrs}$ prior to immunostaining. Ovaries were permeabilized in solution containing $0.2 \%$ polyvinyl alcohol (PVA), $0.1 \% \mathrm{NaBH} 4$, and $1.5 \%$ TritonX-100 in PBS for $4 \mathrm{hrs}$, and incubated in blocking solution $(10 \%$ goat serum, $3 \%$ BSA, $0.15 \%$ glycine $\mathrm{pH} 7.4,0.1 \%$ Triton $\mathrm{X}-100,0.2 \%$ sodium azide, 100 units $/ \mathrm{mL}$ penicillin, and $100 \mathrm{ng} / \mathrm{mL}$ streptomycin, in PBS) overnight. Primary antibody incubation was performed at room temperature with gentle rocking for 2-4 days. Primary antibodies used were mouse anti-p63 (4A4, Biocare Medical, CM163A) and rabbit anti-DDX4 (Abcam, ab13840). Ovaries were washed with wash solution $(0.2 \%$ PVA and $0.15 \%$ Triton$\mathrm{X} 100$, in PBS) for 1-2 days with buffer changes $(2 \mathrm{x}$ daily). Ovaries were next incubated with Alexa Fluor secondary antibodies for 2-3 days followed by washing for 1-2 days with buffer changes.

\section{Optical clearing, imaging, and quantification of oocytes}

Optical clearing of immunostained ovaries was performed as described in (159). Briefly, ovaries were cleared using ScaleS4(0) (40\% D-(-)-sorbitol (w/v), $4 \mathrm{M}$ urea, 10\% glycerol, and 20\% DMSO, in PBS). ScaleS4(0) solution was refreshed twice daily until tissues became cleared (23 days). The membranes with ovaries were mounted using CoverWell Incubation Chamber (Research Products International) and imaged using a Leica DM550 microscope. Images were collected as Z-stacks $(5 \mu \mathrm{m})$ and used to generate maximum projection image in LAS $\mathrm{X}$ software. Oocytes were counted on maximum projection whole ovary images using oocyte markers DDX4 (cytoplasmic staining) and p63 (nuclear staining). Small oocytes with diameter less than $30 \mu \mathrm{m}$ (delineated by DDX4 staining) were categorized as primordial oocytes and larger than $30 \mu \mathrm{m}$ were categorized as growing oocytes (corresponding to growing follicles including primary and secondary follicles). Percentage survival was calculated by dividing the mean of the treatment group counts by the mean of the control group counts and multiplying by a factor of 100 .

\section{Immunoblot}

Protein extracts were prepared with RIPA buffer supplemented with protease and phosphatase inhibitors (Sigma-Aldrich) using a minipestle or Bioruptor Pico (Diagenode). Proteins were resolved in 10\% acrylamide gel and transferred to nitrocellulose membranes. Primary antibodies used in this study were rabbit anti-p63 (Cell Signaling Technology, 13109), rabbit anti-p53 (Leica, CM5P), mouse anti- $\gamma \mathrm{H} 2 \mathrm{AX}$, rabbit anti-DDX4, and mouse anti-ACTB (GeneTex, GT5512). After incubation with HRP secondary antibody, signals were detected using Luminata Forte/Crescendo Western HRP substrate (Millipore). For probing with multiple antibodies, membranes were stripped by using western blot stripping buffer Restore (Thermo Scientific).

\section{Statistics}

Statistical analysis was performed using PRISM 9.0 (GraphPad Software). To analyze the difference between more than two independent groups (e.g. vehicle vs drug doses) statistical analysis was performed by one-way ANOVA and the significance was determined by 
Bonferroni multiple comparison test or Kruskal-Wallis for nonparametric data with Dunn's multiple comparison test. For pairwise comparisons (e.g. wildtype vs. mutant) significance was determined by $t$ test or Mann-Whitney nonparametric test. Values of $\mathrm{P}<0.05$ were considered statistically significant. Data are presented as means \pm
SEM. $* \mathrm{P}<0.05 ; * * \mathrm{P}<0.01 ; * * * \mathrm{P}<0.001 ; \mathrm{P}<0.0001 ;$ n.s., non-significant. 
bioRxiv preprint doi: https://doi.org/10.1101/2021.09.23.461589; this version posted September 24, 2021. The copyright holder for this preprint (which was not certified by peer review) is the author/funder. All rights reserved. No reuse allowed without permission.

\section{Bibliography}

1. Vabre P, Gatimel N, Moreau J, Gayrard V, Picard-Hagen N, Parinaud J, et al. Environmental pollutants, a possible etiology for premature ovarian insufficiency: a narrative review of animal and human data. Environ Health. 2017 Apr $7 ; 16(1): 37$.

2. Richardson MC, Guo M, Fauser BCJM, Macklon NS. Environmental and developmental origins of ovarian reserve. Hum Reprod Update. 2014 Jun;20(3):353-369.

3. Pelosi E, Simonsick E, Forabosco A, Garcia-Ortiz JE, Schlessinger D. Dynamics of the ovarian reserve and impact of genetic and epidemiological factors on age of menopause. Biol Reprod. 2015 May;92(5):130.

4. Hart RJ. Physiological aspects of female fertility: role of the environment, modern lifestyle, and genetics. Physiol Rev. 2016 Jul;96(3):873-909.

5. Fujimoto VY, Bloom MS. Role of environmental factors and gonadotoxin exposure in unexplained female infertility. In: Schattman GL, Esteves SC, Agarwal A, editors. Unexplained Infertility. New York, NY: Springer New York; 2015. p. 161-173.

6. Hernández-Angeles C, Castelo-Branco C. Early menopause: A hazard to a woman's health. Indian J Med Res. 2016 Apr;143(4):420-427.

7. Sharara FI, Seifer DB, Flaws JA. Environmental toxicants and female reproduction 44Additional references are available from the authors. Fertil Steril. 1998 Oct;70(4):613-622.

8. Davis SR, Lambrinoudaki I, Lumsden M, Mishra GD, Pal L, Rees M, et al. Menopause. Nat Rev Dis Primers. 2015 Apr 23;1:15004.

9. Chemaitilly W, Li Z, Krasin MJ, Brooke RJ, Wilson CL, Green DM, et al. Premature ovarian insufficiency in childhood cancer survivors: A report from the st. jude lifetime cohort. J Clin Endocrinol Metab. 2017 Jul 1;102(7):2242-2250.

10. Santoro NF, Wierman ME, Canty-Woessner C. Nonreproductive Conditions Associated with Primary Ovarian Insufficiency (POI). In: Santoro NF, Cooper AR, editors. Primary Ovarian Insufficiency. Cham: Springer International Publishing; 2016. p. 101-114.

11. Gargus E, Deans R, Anazodo A, Woodruff TK. Management of primary ovarian insufficiency symptoms in survivors of childhood and adolescent cancer. J Natl Compr Canc Netw. 2018;16(9):1137-1149.

12. Chemaitilly W, Mertens AC, Mitby P, Whitton J, Stovall M, Yasui Y, et al. Acute ovarian failure in the childhood cancer survivor study. J Clin Endocrinol Metab. 2006 May;91(5):1723-1728.

13. Green DM, Sklar CA, Boice JD, Mulvihill JJ, Whitton JA, Stovall M, et al. Ovarian failure and reproductive outcomes after childhood cancer treatment: results from the Childhood Cancer Survivor Study. J Clin Oncol. 2009 May 10;27(14):2374-2381.

14. Larsen EC, Müller J, Schmiegelow K, Rechnitzer C, Andersen AN. Reduced ovarian function in long-term survivors of radiation- and chemotherapy-treated childhood cancer. J Clin Endocrinol Metab. 2003 Nov;88(11):53075314.

15. Overbeek A, van den Berg MH, van Leeuwen FE, Kaspers GJL, Lambalk CB, van Dulmen-den Broeder E. Chemotherapy-related late adverse effects on ovarian function in female survivors of childhood and young adult cancer: A systematic review. Cancer Treat Rev. 2017 Feb;53:10-24.

16. Sklar CA, Mertens AC, Mitby P, Whitton J, Stovall M, Kasper C, et al. Premature menopause in survivors of childhood cancer: a report from the childhood cancer survivor study. J Natl Cancer Inst. 2006 Jul 5;98(13):890-896.

17. Green DM, Kawashima T, Stovall M, Leisenring W, Sklar CA, Mertens AC, et al. Fertility of female survivors of childhood cancer: a report from the childhood cancer survivor study. J Clin Oncol. 2009 Jun 1;27(16):2677-2685.

18. Kim S-Y, Kim SK, Lee JR, Woodruff TK. Toward precision medicine for preserving fertility in cancer patients: existing and emerging fertility preservation options for women. J Gynecol Oncol. 2016 Mar;27(2):e22.

19. Mahajan N. Fertility preservation in female cancer patients: An overview. J Hum Reprod Sci. 2015 Mar;8(1):3-13.

20. Anderson RA, Mitchell RT, Kelsey TW, Spears N, Telfer EE, Wallace WHB. Cancer treatment and gonadal function: experimental and established strategies for fertility preservation in children and young adults. Lancet Diabetes Endocrinol. 2015 Jul;3(7):556-567.

21. Oktay K, Oktem O. Ovarian cryopreservation and transplantation for fertility preservation for medical indications: report of an ongoing experience. Fertil Steril. $2010 \mathrm{Feb}$;93(3):762-768.

22. Jadoul P, Guilmain A, Squifflet J, Luyckx M, Votino R, Wyns C, et al. Efficacy of ovarian tissue cryopreservation for fertility preservation: lessons learned from 545 cases. Hum Reprod. 2017 May 1;32(5):1046-1054.

23. Biasin E, Salvagno F, Berger M, Nesi F, Quarello P, Vassallo E, et al. Ovarian tissue cryopreservation in girls undergoing haematopoietic stem cell transplant: experience of a single centre. Bone Marrow Transplant. 2015 Sep;50(9):1206-1211. 
24. Wallace WHB, Kelsey TW, Anderson RA. Fertility preservation in pre-pubertal girls with cancer: the role of ovarian tissue cryopreservation. Fertil Steril. 2016 Jan;105(1):6-12.

25. Kerr JB, Hutt KJ, Michalak EM, Cook M, Vandenberg CJ, Liew SH, et al. DNA damage-induced primordial follicle oocyte apoptosis and loss of fertility require TAp63-mediated induction of Puma and Noxa. Mol Cell. 2012 Nov 9;48(3):343-352.

26. Bolcun-Filas E, Rinaldi VD, White ME, Schimenti JC. Reversal of female infertility by Chk2 ablation reveals the oocyte DNA damage checkpoint pathway. Science. 2014 Jan 31;343(6170):533-536.

27. Soleimani R, Heytens E, Darzynkiewicz Z, Oktay K. Mechanisms of chemotherapy-induced human ovarian aging: double strand DNA breaks and microvascular compromise. Aging (Albany, NY). 2011 Aug;3(8):782-793.

28. Gebel J, Tuppi M, Sänger N, Schumacher B, Dötsch V. DNA damaged induced cell death in oocytes. Molecules. 2020 Dec 3;25(23).

29. Fridman JS, Lowe SW. Control of apoptosis by p53. Oncogene. 2003 Dec 8;22(56):9030-9040.

30. Haupt S, Berger M, Goldberg Z, Haupt Y. Apoptosis - the p53 network. J Cell Sci. 2003 Oct 15;116(Pt 20):40774085.

31. Pietsch EC, Sykes SM, McMahon SB, Murphy ME. The p53 family and programmed cell death. Oncogene. 2008 Oct 27;27(50):6507-6521.

32. Tuppi M, Kehrloesser S, Coutandin DW, Rossi V, Luh LM, Strubel A, et al. Oocyte DNA damage quality control requires consecutive interplay of CHK2 and CK1 to activate p63. Nat Struct Mol Biol. 2018 Feb 26;25(3):261-269.

33. Nguyen Q-N, Zerafa N, Liew SH, Morgan FH, Strasser A, Scott CL, et al. Loss of PUMA protects the ovarian reserve during DNA-damaging chemotherapy and preserves fertility. Cell Death Dis. 2018 May 23;9(6):618.

34. Kim S-Y, Nair DM, Romero M, Serna VA, Koleske AJ, Woodruff TK, et al. Transient inhibition of p53 homologs protects ovarian function from two distinct apoptotic pathways triggered by anticancer therapies. Cell Death Differ. 2019;26(3):502-515.

35. Luan Y, Edmonds ME, Woodruff TK, Kim S-Y. Inhibitors of apoptosis protect the ovarian reserve from cyclophosphamide. J Endocrinol. 2019 Feb 1;240(2):243-256.

36. Rinaldi VD, Hsieh K, Munroe R, Bolcun-Filas E, Schimenti JC. Pharmacological Inhibition of the DNA Damage Checkpoint Prevents Radiation-Induced Oocyte Death. Genetics. 2017 Jun 2;206(4):1823-1828.

37. Mazur L, Opydo-Chanek M, Stojak M, Wojcieszek K. Mafosfamide as a new anticancer agent: preclinical investigations and clinical trials. Anticancer Res. 2012 Jul;32(7):2783-2789.

38. Spears N, Lopes F, Stefansdottir A, Rossi V, De Felici M, Anderson RA, et al. Ovarian damage from chemotherapy and current approaches to its protection. Hum Reprod Update. 2019 Nov 5;25(6):673-693.

39. Anderson RA, Spears N. Cancer treatment and the ovary: Clinical and laboratory analysis of ovarian toxicity. Amsterdam: Elsevier/Academic Press; 2015.

40. Morgan S, Lopes F, Gourley C, Anderson RA, Spears N. Cisplatin and doxorubicin induce distinct mechanisms of ovarian follicle loss; imatinib provides selective protection only against cisplatin. PLoS One. 2013 Jul 29;8(7):e70117.

41. Morgan S, Anderson RA, Gourley C, Wallace WH, Spears N. How do chemotherapeutic agents damage the ovary? Hum Reprod Update. 2012 Oct;18(5):525-535.

42. Goldstein M, Roos WP, Kaina B. Apoptotic death induced by the cyclophosphamide analogue mafosfamide in human lymphoblastoid cells: contribution of DNA replication, transcription inhibition and Chk/p53 signaling. Toxicol Appl Pharmacol. 2008 May 15;229(1):20-32.

43. De Roo C, Lierman S, Tilleman K, De Sutter P. In-vitro fragmentation of ovarian tissue activates primordial follicles through the Hippo pathway. Hum Reprod Open. 2020 Nov 16;2020(4):hoaa048.

44. Kalich-Philosoph L, Roness H, Carmely A, Fishel-Bartal M, Ligumsky H, Paglin S, et al. Cyclophosphamide triggers follicle activation and "burnout"; AS101 prevents follicle loss and preserves fertility. Sci Transl Med. 2013 May 15;5(185):185ra62.

45. Lande Y, Fisch B, Tsur A, Farhi J, Prag-Rosenberg R, Ben-Haroush A, et al. Short-term exposure of human ovarian follicles to cyclophosphamide metabolites seems to promote follicular activation in vitro. Reprod Biomed Online. 2017 Jan;34(1):104-114.

46. Roness H, Gavish Z, Cohen Y, Meirow D. Ovarian follicle burnout: A universal phenomenon? Cell Cycle. 2013 Oct 15;12(20):3245-3246.

47. Eldani M, Luan Y, Xu PC, Bargar T, Kim S-Y. Continuous treatment with cisplatin induces the oocyte death of primordial follicles without activation. FASEB J. 2020 Aug 23;34(10):13885-13899.

48. Titus S, Szymanska KJ, Musul B, Turan V, Taylan E, Garcia-Milian R, et al. Individual-oocyte transcriptomic analysis shows that genotoxic chemotherapy depletes human primordial follicle reserve in vivo by triggering proapoptotic pathways without growth activation. Sci Rep. 2021 Jan 11;11(1):407. 
49. Nguyen QN, Zerafa N, Liew SH, Findlay JK, Hickey M, Hutt KJ. Cisplatin- and cyclophosphamide-induced primordial follicle depletion is caused by direct damage to oocytes. Mol Hum Reprod. 2019 Aug 1;25(8):433-444.

50. Goldman KN, Chenette D, Arju R, Duncan FE, Keefe DL, Grifo JA, et al. mTORC1/2 inhibition preserves ovarian function and fertility during genotoxic chemotherapy. Proc Natl Acad Sci USA. 2017 Mar 21;114(12):3186-3191.

51. Rinaldi VD, Bolcun-Filas E, Kogo H, Kurahashi H, Schimenti JC. The DNA damage checkpoint eliminates mouse oocytes with chromosome synapsis failure. Mol Cell. 2017 Sep 21;67(6):1026-1036.e2.

52. Stringer JM, Winship A, Zerafa N, Wakefield M, Hutt K. Oocytes can efficiently repair DNA double-strand breaks to restore genetic integrity and protect offspring health. Proc Natl Acad Sci USA. 2020 May 26;117(21):11513-11522.

53. Bellusci G, Mattiello L, Iannizzotto V, Ciccone S, Maiani E, Villani V, et al. Kinase-independent inhibition of cyclophosphamide-induced pathways protects the ovarian reserve and prolongs fertility. Cell Death Dis. 2019 Sep 27;10(10):726.

54. Zimmermann M, de Lange T. 53BP1: pro choice in DNA repair. Trends Cell Biol. 2014 Feb;24(2):108-117.

55. Daley JM, Sung P. 53BP1, BRCA1, and the choice between recombination and end joining at DNA double-strand breaks. Mol Cell Biol. 2014 Apr;34(8):1380-1388.

56. Gupta A, Hunt CR, Chakraborty S, Pandita RK, Yordy J, Ramnarain DB, et al. Role of 53BP1 in the regulation of DNA double-strand break repair pathway choice. Radiat Res. 2014 Jan;181(1):1-8.

57. Roti Roti EC, Leisman SK, Abbott DH, Salih SM. Acute doxorubicin insult in the mouse ovary is cell- and follicletype dependent. PLoS One. 2012 Aug 2;7(8):e42293.

58. Coutandin D, Osterburg C, Srivastav RK, Sumyk M, Kehrloesser S, Gebel J, et al. Quality control in oocytes by p63 is based on a spring-loaded activation mechanism on the molecular and cellular level. Elife. 2016 Mar 14;5.

59. Deutsch GB, Zielonka EM, Coutandin D, Weber TA, Schäfer B, Hannewald J, et al. DNA damage in oocytes induces a switch of the quality control factor TAp63 $\alpha$ from dimer to tetramer. Cell. 2011 Feb 18;144(4):566-576.

60. Liu Q, Guntuku S, Cui XS, Matsuoka S, Cortez D, Tamai K, et al. Chk1 is an essential kinase that is regulated by Atr and required for the G(2)/M DNA damage checkpoint. Genes Dev. 2000 Jun 15;14(12):1448-1459.

61. Engelke CG, Parsels LA, Qian Y, Zhang Q, Karnak D, Robertson JR, et al. Sensitization of pancreatic cancer to chemoradiation by the Chk1 inhibitor MK8776. Clin Cancer Res. 2013 Aug 15;19(16):4412-4421.

62. Duong H-Q, Hong YB, Kim JS, Lee H-S, Yi YW, Kim YJ, et al. Inhibition of checkpoint kinase 2 (CHK2) enhances sensitivity of pancreatic adenocarcinoma cells to gemcitabine. J Cell Mol Med. 2013 Oct;17(10):1261-1270.

63. McNeely S, Beckmann R, Bence Lin AK. CHEK again: revisiting the development of CHK1 inhibitors for cancer therapy. Pharmacol Ther. 2014 Apr;142(1):1-10.

64. Xiao Y, Ramiscal J, Kowanetz K, Del Nagro C, Malek S, Evangelista M, et al. Identification of preferred chemotherapeutics for combining with a CHK1 inhibitor. Mol Cancer Ther. 2013 Nov;12(11):2285-2295.

65. Garrett MD, Collins I. Anticancer therapy with checkpoint inhibitors: what, where and when? Trends Pharmacol Sci. 2011 May;32(5):308-316.

66. Takai H, Naka K, Okada Y, Watanabe M, Harada N, Saito S, et al. Chk2-deficient mice exhibit radioresistance and defective p53-mediated transcription. EMBO J. 2002 Oct 1;21(19):5195-5205.

67. Hirao A, Kong YY, Matsuoka S, Wakeham A, Ruland J, Yoshida H, et al. DNA damage-induced activation of p53 by the checkpoint kinase Chk2. Science. 2000 Mar 10;287(5459):1824-1827.

68. Seto T, Esaki T, Hirai F, Arita S, Nosaki K, Makiyama A, et al. Phase I, dose-escalation study of AZD7762 alone and in combination with gemcitabine in Japanese patients with advanced solid tumours. Cancer Chemother Pharmacol. 2013 Sep;72(3):619-627.

69. Sausville E, Lorusso P, Carducci M, Carter J, Quinn MF, Malburg L, et al. Phase I dose-escalation study of AZD7762, a checkpoint kinase inhibitor, in combination with gemcitabine in US patients with advanced solid tumors. Cancer Chemother Pharmacol. 2014 Mar;73(3):539-549.

70. Wang L, Wang Y, Chen A, Jalali A, Liu S, Guo Y, et al. Effects of a checkpoint kinase inhibitor, AZD7762, on tumor suppression and bone remodeling. Int J Oncol. 2018 Sep;53(3):1001-1012.

71. Liu B, Chen W, Li H, Li F, Jin X, Li Q. Radiosensitization of NSCLC cells to X-rays and carbon ions by the CHK1/CHK2 inhibitor AZD7762, Honokiol and Tunicamycin. Radiat Environ Biophys. 2020 Aug 28;59(4):723-732.

72. Liu Y, Li Y, Wang X, Liu F, Gao P, Quinn MM, et al. Gemcitabine and Chk1 Inhibitor AZD7762 Synergistically Suppress the Growth of Lkb1-Deficient Lung Adenocarcinoma. Cancer Res. 2017 Sep 15;77(18):5068-5076.

73. Cho H-W, Lee S, Min K-J, Hong JH, Song JY, Lee JK, et al. Advances in the Treatment and Prevention of Chemotherapy-Induced Ovarian Toxicity. Int J Mol Sci. 2020 Oct 21;21(20).

74. Stefansdottir A, Johnston ZC, Powles-Glover N, Anderson RA, Adams IR, Spears N. Etoposide damages female germ cells in the developing ovary. BMC Cancer. 2016 Aug 11;16(1):482.

75. IARC Working Group on the Evaluation of Carcinogenic Risks to Humans. ETOPOSIDE IN COMBINATION WITH CISPLATIN AND BLEOMYCIN - Pharmaceuticals - NCBI Bookshelf. 2012; 
76. Agatsuma T, Koizumi T, Kanda S, Ito M, Urushihata K, Yamamoto H, et al. Combination chemotherapy with doxorubicin, vincristine, cyclophosphamide, and platinum compounds for advanced thymic carcinoma. J Thorac Oncol. 2011 Dec;6(12):2130-2134.

77. Lopes F, Liu J, Morgan S, Matthews R, Nevin L, Anderson RA, et al. Single and combined effects of cisplatin and doxorubicin on the human and mouse ovary in vitro. Reproduction. 2019 Dec 1;

78. Juan CA, Pérez de la Lastra JM, Plou FJ, Pérez-Lebeña E. The chemistry of reactive oxygen species (ROS) revisited: outlining their role in biological macromolecules (DNA, lipids and proteins) and induced pathologies. Int $\mathrm{J}$ Mol Sci. 2021 Apr 28;22(9).

79. Winship AL, Stringer JM, Liew SH, Hutt KJ. The importance of DNA repair for maintaining oocyte quality in response to anti-cancer treatments, environmental toxins and maternal ageing. Hum Reprod Update. 2018 Mar $1 ; 24(2): 119-134$

80. Pecoraro M, Pala B, Di Marcantonio MC, Muraro R, Marzocco S, Pinto A, et al. Doxorubicin-induced oxidative and nitrosative stress: Mitochondrial connexin 43 is at the crossroads. Int J Mol Med. 2020 Sep;46(3):1197-1209.

81. Cappetta D, De Angelis A, Sapio L, Prezioso L, Illiano M, Quaini F, et al. Oxidative stress and cellular response to doxorubicin: A common factor in the complex milieu of anthracycline cardiotoxicity. Oxid Med Cell Longev. 2017 Oct 18;2017:1521020.

82. Conklin KA. Chemotherapy-associated oxidative stress: impact on chemotherapeutic effectiveness. Integr Cancer Ther. 2004 Dec;3(4):294-300.

83. Gorini S, De Angelis A, Berrino L, Malara N, Rosano G, Ferraro E. Chemotherapeutic drugs and mitochondrial dysfunction: focus on doxorubicin, trastuzumab, and sunitinib. Oxid Med Cell Longev. 2018 Mar 18;2018:7582730.

84. Kropp J, Roti Roti EC, Ringelstetter A, Khatib H, Abbott DH, Salih SM. Dexrazoxane Diminishes DoxorubicinInduced Acute Ovarian Damage and Preserves Ovarian Function and Fecundity in Mice. PLoS One. 2015 Nov 6;10(11): 0142588.

85. Roti Roti EC, Salih SM. Dexrazoxane ameliorates doxorubicin-induced injury in mouse ovarian cells. Biol Reprod. 2012 Mar 30;86(3):96.

86. Han J, Wang H, Zhang T, Chen Z, Zhao T, Lin L, et al. Resveratrol attenuates doxorubicin-induced meiotic failure through inhibiting oxidative stress and apoptosis in mouse oocytes. Aging (Albany, NY). 2020 Apr 30;12(9):77177728.

87. Wang Y, Liu M, Johnson SB, Yuan G, Arriba AK, Zubizarreta ME, et al. Doxorubicin obliterates mouse ovarian reserve through both primordial follicle atresia and overactivation. Toxicol Appl Pharmacol. 2019 Oct 15;381:114714.

88. Zhao H, Traganos F, Albino AP, Darzynkiewicz Z. Oxidative stress induces cell cycle-dependent Mre11 recruitment, ATM and Chk2 activation and histone H2AX phosphorylation. Cell Cycle. 2008 May 15;7(10):14901495.

89. Hsu P-C, Gopinath RK, Hsueh Y-A, Shieh S-Y. CHK2-mediated regulation of PARP1 in oxidative DNA damage response. Oncogene. 2019;38(8):1166-1182.

90. Guo Q-Q, Wang S-S, Zhang S-S, Xu H-D, Li X-M, Guan Y, et al. ATM-CHK2-Beclin 1 axis promotes autophagy to maintain ROS homeostasis under oxidative stress. EMBO J. 2020 Mar 18; e103111.

91. Koczor CA, Shokolenko IN, Boyd AK, Balk SP, Wilson GL, LeDoux SP. Mitochondrial DNA damage initiates a cell cycle arrest by a Chk2-associated mechanism in mammalian cells. J Biol Chem. 2009 Dec 25;284(52):3619136201.

92. Livera G, Petre-Lazar B, Guerquin M-J, Trautmann E, Coffigny H, Habert R. p63 null mutation protects mouse oocytes from radio-induced apoptosis. Reproduction. 2008 Jan;135(1):3-12.

93. Suh E-K, Yang A, Kettenbach A, Bamberger C, Michaelis AH, Zhu Z, et al. p63 protects the female germ line during meiotic arrest. Nature. 2006 Nov 30;444(7119):624-628.

94. Gebel J, Tuppi M, Chaikuad A, Hötte K, Schulz L, Löhr F, et al. p63 sets the threshold for induction of apoptosis using a kinetically encoded "doorbell-like" mechanism. BioRxiv. 2019 Jun 24;

95. Gonfloni S, Di Tella L, Caldarola S, Cannata SM, Klinger FG, Di Bartolomeo C, et al. Inhibition of the c-AblTAp63 pathway protects mouse oocytes from chemotherapy-induced death. Nat Med. 2009 Oct;15(10):1179-1185.

96. Davies SP, Reddy H, Caivano M, Cohen P. Specificity and mechanism of action of some commonly used protein kinase inhibitors. Biochem J. 2000 Oct 1;351(Pt 1):95-105.

97. Menolfi D, Zha S. ATM, ATR and DNA-PKcs kinases-the lessons from the mouse models: inhibition $\neq$ deletion. Cell Biosci. 2020 Jan 29;10:8.

98. Smith J, Tho LM, Xu N, Gillespie DA. The ATM-Chk2 and ATR-Chk1 pathways in DNA damage signaling and cancer. Adv Cancer Res. 2010;108:73-112.

99. Maréchal A, Zou L. DNA damage sensing by the ATM and ATR kinases. Cold Spring Harb Perspect Biol. 2013 Sep 1;5(9). 
100. Blackford AN, Jackson SP. ATM, ATR, and DNA-PK: The Trinity at the Heart of the DNA Damage Response. Mol Cell. 2017 Jun 15;66(6):801-817.

101. Kerr JB, Hutt KJ, Cook M, Speed TP, Strasser A, Findlay JK, et al. Cisplatin-induced primordial follicle oocyte killing and loss of fertility are not prevented by imatinib. Nat Med. 2012 Aug;18(8):1170-2; author reply 1172.

102. Maiani E, Di Bartolomeo C, Klinger FG, Cannata SM, Bernardini S, Chateauvieux S, et al. Reply to: Cisplatininduced primordial follicle oocyte killing and loss of fertility are not prevented by imatinib. Nat Med. 2012 Aug;18(8):1172-1174.

103. Kim SY, Cordeiro MH, Serna VA, Ebbert K, Butler LM, Sinha S, et al. Rescue of platinum-damaged oocytes from programmed cell death through inactivation of the p53 family signaling network. Cell Death Differ. 2013 Aug;20(8):987-997.

104. Hao X, Anastácio A, Rodriguez-Wallberg KA. Investigation of apoptosis and follicle activation by proteomics in an experimental model of cyclophosphamide-induced follicle depletion in ovarian culture. Fertil Steril. 2020 Sep;114(3):e74-e75.

105. Mattiello L, Pucci G, Marchetti F, Diederich M, Gonfloni S. Asciminib mitigates DNA damage stress signaling induced by cyclophosphamide in the ovary. Int J Mol Sci. 2021 Jan 30;22(3).

106. Petrillo SK, Desmeules P, Truong T-Q, Devine PJ. Detection of DNA damage in oocytes of small ovarian follicles following phosphoramide mustard exposures of cultured rodent ovaries in vitro. Toxicol Appl Pharmacol. 2011 Jun 1;253(2):94-102.

107. Jeelani R, Khan SN, Shaeib F, Kohan-Ghadr H-R, Aldhaheri SR, Najafi T, et al. Cyclophosphamide and acrolein induced oxidative stress leading to deterioration of metaphase II mouse oocyte quality. Free Radic Biol Med. 2017 Sep;110:11-18.

108. Liu X, Fan L, Lu C, Yin S, Hu H. Functional Role of p53 in the Regulation of Chemical-Induced Oxidative Stress. Oxid Med Cell Longev. 2020 Feb 28;2020:6039769.

109. Yu W, Chen Y, Dubrulle J, Stossi F, Putluri V, Sreekumar A, et al. Cisplatin generates oxidative stress which is accompanied by rapid shifts in central carbon metabolism. Sci Rep. 2018 Mar 9;8(1):4306.

110. Marullo R, Werner E, Degtyareva N, Moore B, Altavilla G, Ramalingam SS, et al. Cisplatin induces a mitochondrial-ROS response that contributes to cytotoxicity depending on mitochondrial redox status and bioenergetic functions. PLoS One. 2013 Nov 19;8(11):e81162.

111. Azzam EI, Jay-Gerin J-P, Pain D. Ionizing radiation-induced metabolic oxidative stress and prolonged cell injury. Cancer Lett. 2012 Dec 31;327(1-2):48-60.

112. Stindt MH, Muller PAJ, Ludwig RL, Kehrloesser S, Dötsch V, Vousden KH. Functional interplay between MDM2, p63/p73 and mutant p53. Oncogene. 2015 Aug 13;34(33):4300-4310.

113. Davison TS, Vagner C, Kaghad M, Ayed A, Caput D, Arrowsmith CH. p73 and p63 are homotetramers capable of weak heterotypic interactions with each other but not with p53. J Biol Chem. 1999 Jun 25;274(26):18709-18714.

114. Strano S, Fontemaggi G, Costanzo A, Rizzo MG, Monti O, Baccarini A, et al. Physical interaction with human tumor-derived p53 mutants inhibits p63 activities. J Biol Chem. 2002 May 24;277(21):18817-18826.

115. Michalak EM, Villunger A, Adams JM, Strasser A. In several cell types tumour suppressor p53 induces apoptosis largely via Puma but Noxa can contribute. Cell Death Differ. 2008 Jun;15(6):1019-1029.

116. Shibue T, Takeda K, Oda E, Tanaka H, Murasawa H, Takaoka A, et al. Integral role of Noxa in p53-mediated apoptotic response. Genes Dev. 2003 Sep 15;17(18):2233-2238.

117. Nakano K, Vousden KH. PUMA, a novel proapoptotic gene, is induced by p53. Mol Cell. 2001 Mar;7(3):683-694.

118. You H, Pellegrini M, Tsuchihara K, Yamamoto K, Hacker G, Erlacher M, et al. FOXO3a-dependent regulation of Puma in response to cytokine/growth factor withdrawal. J Exp Med. 2006 Jul 10;203(7):1657-1663.

119. Dudgeon C, Wang P, Sun X, Peng R, Sun Q, Yu J, et al. PUMA induction by FoxO3a mediates the anticancer activities of the broad-range kinase inhibitor UCN-01. Mol Cancer Ther. 2010 Nov;9(11):2893-2902.

120. Liu H, Luo L-L, Qian Y-S, Fu Y-C, Sui X-X, Geng Y-J, et al. FOXO3a is involved in the apoptosis of naked oocytes and oocytes of primordial follicles from neonatal rat ovaries. Biochem Biophys Res Commun. 2009 Apr 17;381(4):722-727.

121. Tsai W-B, Chung YM, Takahashi Y, Xu Z, Hu MC-T. Functional interaction between FOXO3a and ATM regulates DNA damage response. Nat Cell Biol. 2008 Apr;10(4):460-467.

122. Chung YM, Park S-H, Tsai W-B, Wang S-Y, Ikeda M-A, Berek JS, et al. FOXO3 signalling links ATM to the p53 apoptotic pathway following DNA damage. Nat Commun. 2012;3:1000.

123. Fasano C, Disciglio V, Bertora S, Lepore Signorile M, Simone C. FOXO3a from the Nucleus to the Mitochondria: A Round Trip in Cellular Stress Response. Cells. 2019 Sep 19;8(9).

124. Ferber EC, Peck B, Delpuech O, Bell GP, East P, Schulze A. FOXO3a regulates reactive oxygen metabolism by inhibiting mitochondrial gene expression. Cell Death Differ. 2012 Jun;19(6):968-979. 
125. Yalcin S, Zhang X, Luciano JP, Mungamuri SK, Marinkovic D, Vercherat C, et al. Foxo3 is essential for the regulation of ataxia telangiectasia mutated and oxidative stress-mediated homeostasis of hematopoietic stem cells. $\mathrm{J}$ Biol Chem. 2008 Sep 12;283(37):25692-25705.

126. Kidder GM, Vanderhyden BC. Bidirectional communication between oocytes and follicle cells: ensuring oocyte developmental competence. Can J Physiol Pharmacol. 2010 Apr;88(4):399-413.

127. Eppig JJ. Reproduction: oocytes call, granulosa cells connect. Curr Biol. 2018 Apr 23;28(8):R354-R356.

128. Clarke HJ. Mechanisms and function of germ line-somatic communication during mammalian follicular growth. Current Opinion in Endocrine and Metabolic Research. 2021 Jun;18:216-223.

129. Rodrigues P, Limback D, McGinnis L, Marques M, Aibar J, Plancha CE. Germ-Somatic Cell Interactions Are Involved in Establishing the Follicle Reserve in Mammals. Front Cell Dev Biol. 2021 Jun 14;9:674137.

130. Mukherjee S, Dutta A, Chakraborty A. External modulators and redox homeostasis: Scenario in radiation-induced bystander cells. Mutat Res Rev Mutat Res. 2021 Jun;787:108368.

131. Najafi M, Fardid R, Hadadi G, Fardid M. The mechanisms of radiation-induced bystander effect. J Biomed Phys Eng. 2014 Dec 15;4(4):163-172.

132. Di X, Bright AT, Bellott R, Gaskins E, Robert J, Holt S, et al. A chemotherapy-associated senescence bystander effect in breast cancer cells. Cancer Biol Ther. 2008 Jun;7(6):864-872.

133. Cilliers C, Thurber GM. Standing by" for Bystander Effects: Dual-Isotope Imaging of Antibody-Drug Conjugate and Payload Distribution. J Nucl Med. 2018 Sep;59(9):1459-1460.

134. Arora S, Heyza JR, Chalfin EC, Ruch RJ, Patrick SM. Gap Junction Intercellular Communication Positively Regulates Cisplatin Toxicity by Inducing DNA Damage through Bystander Signaling. Cancers (Basel). 2018 Oct $2 ; 10(10)$.

135. Azzam EI, de Toledo SM, Little JB. Direct evidence for the participation of gap junction-mediated intercellular communication in the transmission of damage signals from alpha -particle irradiated to nonirradiated cells. Proc Natl Acad Sci USA. 2001 Jan 16;98(2):473-478.

136. Spray DC, Hanstein R, Lopez-Quintero SV, Stout RF, Suadicani SO, Thi MM. Gap junctions and Bystander Effects: Good Samaritans and executioners. Wiley Interdiscip Rev Membr Transp Signal. 2013;2(1):1-15.

137. Burdak-Rothkamm S, Rothkamm K, Prise KM. ATM acts downstream of ATR in the DNA damage response signaling of bystander cells. Cancer Res. 2008 Sep 1;68(17):7059-7065.

138. Narayanan PK, Goodwin EH, Lehnert BE. Alpha particles initiate biological production of superoxide anions and hydrogen peroxide in human cells. Cancer Res. 1997 Sep 15;57(18):3963-3971.

139. Jin S, Cordes N. ATM controls DNA repair and mitochondria transfer between neighboring cells. Cell Commun Signal. 2019 Nov 8;17(1):144.

140. Lorimore SA, Rastogi S, Mukherjee D, Coates PJ, Wright EG. The influence of p53 functions on radiation-induced inflammatory bystander-type signaling in murine bone marrow. Radiat Res. 2013 Apr;179(4):406-415.

141. Jaiswal H, Lindqvist A. Bystander communication and cell cycle decisions after DNA damage. Front Genet. 2015 Feb 27;6:63.

142. Sun M-H, Zheng J, Xie F-Y, Shen W, Yin S, Ma J-Y. Cumulus Cells Block Oocyte Meiotic Resumption via Gap Junctions in Cumulus Oocyte Complexes Subjected to DNA Double-Strand Breaks. PLoS One. 2015 Nov 17;10(11):e0143223.

143. Chen L, Zeng Y, Zhou S-F. Role of apoptosis in cancer resistance to chemotherapy. In: Tutar Y, editor. Current Understanding of Apoptosis - Programmed Cell Death. InTech; 2018.

144. Bushweller JH. Targeting transcription factors in cancer - from undruggable to reality. Nat Rev Cancer. 2019 Sep $11 ; 19(11): 611-624$.

145. Huart A-S, MacLaine NJ, Meek DW, Hupp TR. CK1alpha plays a central role in mediating MDM2 control of p53 and E2F-1 protein stability. J Biol Chem. 2009 Nov 20;284(47):32384-32394.

146. Maclaine NJ, Hupp TR. The regulation of $\mathrm{p} 53$ by phosphorylation: a model for how distinct signals integrate into the p53 pathway. Aging (Albany, NY). 2009 May 7;1(5):490-502.

147. Jack MT, Woo RA, Hirao A, Cheung A, Mak TW, Lee PWK. Chk2 is dispensable for p53-mediated G1 arrest but is required for a latent p53-mediated apoptotic response. Proc Natl Acad Sci USA. 2002 Jul 23;99(15):9825-9829.

148. Elyada E, Pribluda A, Goldstein RE, Morgenstern Y, Brachya G, Cojocaru G, et al. CKI $\alpha$ ablation highlights a critical role for p53 in invasiveness control. Nature. 2011 Feb 17;470(7334):409-413.

149. Schittek B, Sinnberg T. Biological functions of casein kinase 1 isoforms and putative roles in tumorigenesis. Mol Cancer. 2014 Oct 11;13:231.

150. Knippschild U, Krüger M, Richter J, Xu P, García-Reyes B, Peifer C, et al. The CK1 family: contribution to cellular stress response and its role in carcinogenesis. Front Oncol. 2014 May 19;4:96. 
151. Du C, Yang H, Feng F, Liu W, Chen Y, Sun H. Achieving effective and selective CK1 inhibitors through structure modification. Future Med Chem. 2021 Mar;13(5):505-528.

152. Brandsma I, Fleuren EDG, Williamson CT, Lord CJ. Directing the use of DDR kinase inhibitors in cancer treatment. Expert Opin Investig Drugs. 2017 Dec;26(12):1341-1355.

153. Stolarova L, Kleiblova P, Janatova M, Soukupova J, Zemankova P, Macurek L, et al. CHEK2 Germline Variants in Cancer Predisposition: Stalemate Rather than Checkmate. Cells. 2020 Dec 12;9(12).

154. Ward LD, Parker MM, Deaton AM, Tu H-C, Flynn-Carroll AO, Hinkle G, et al. Rare coding variants in five DNA damage repair genes associate with timing of natural menopause. medRxiv. 2021 Apr 20;

155. Ruth KS, Day FR, Hussain J, Martínez-Marchal A, Aiken CE, Azad A, et al. Genetic insights into biological mechanisms governing human ovarian ageing. Nature. 2021 Aug 4;

156. Martínez-Marchal A, Huang Y, Guillot-Ferriols MT, Ferrer-Roda M, Guixé A, Garcia-Caldés M, et al. The DNA damage response is required for oocyte cyst breakdown and follicle formation in mice. PLoS Genet. 2020 Nov 18;16(11):e1009067.

157. Tilly JL. Ovarian follicle counts--not as simple as 1, 2, 3. Reprod Biol Endocrinol. 2003 Feb 6;1:11.

158. Myers M, Britt KL, Wreford NGM, Ebling FJP, Kerr JB. Methods for quantifying follicular numbers within the mouse ovary. Reproduction. 2004 May;127(5):569-580.

159. Boateng R, Boechat N, Henrich PP, Bolcun-Filas E. Whole ovary immunofluorescence, clearing, and multiphoton microscopy for quantitative 3D analysis of the developing ovarian reserve in mouse. JOVE. 2021 Sep 3;(175). 

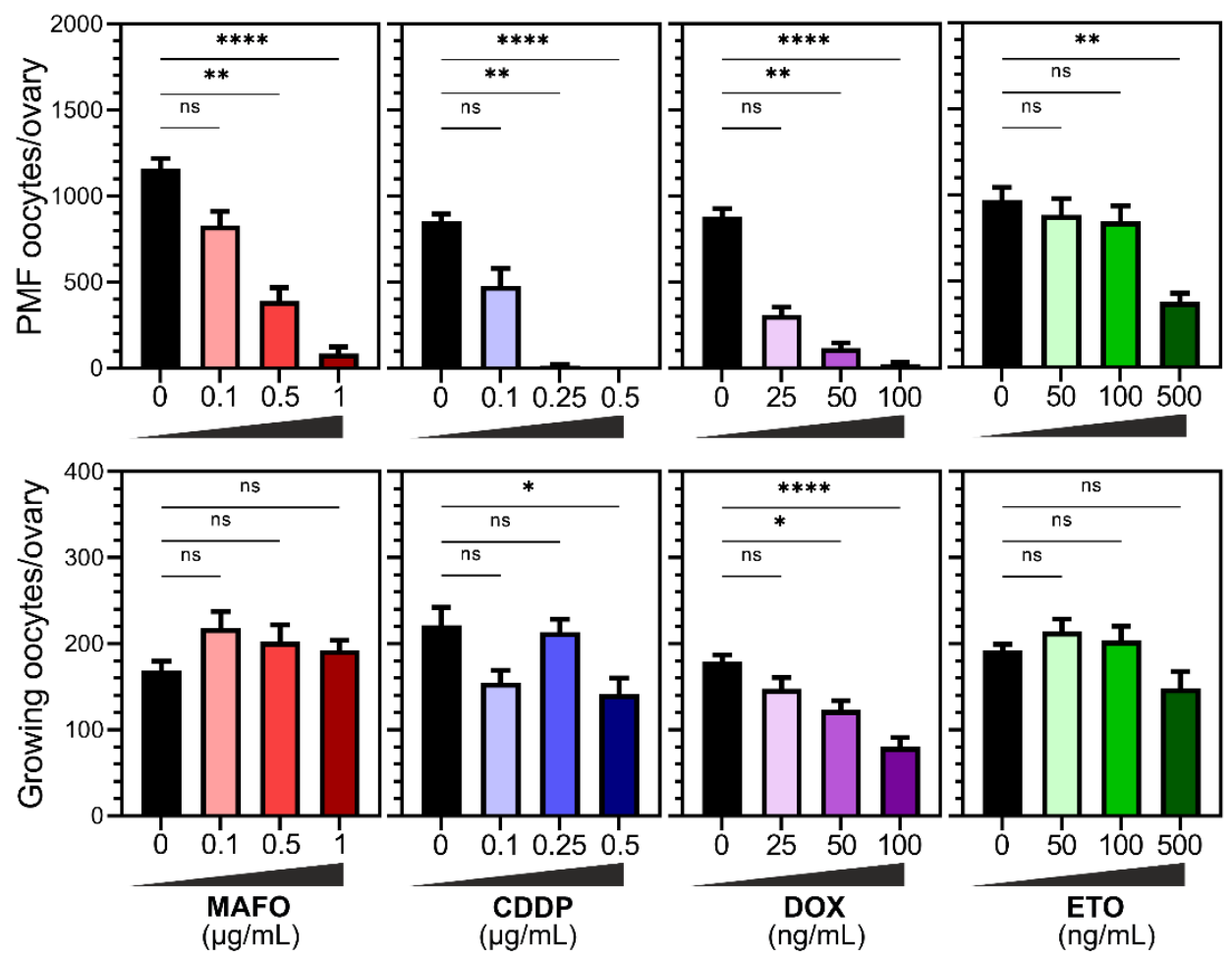

Figure S1. Ovotoxicity of alkylating agents (MAFO and CDDP) and topoisomerase II poisons (DOX and ETO) is dose dependent. Ovaries from wildtype $\mathrm{Tg}($ Pou $5 \mathrm{f} 1$-EGFP)2Mnn/J females were treated for $48 \mathrm{hrs}$ with $\mathrm{MAFO}(0.1,0.5,1 \mu \mathrm{g} / \mathrm{mL})$, $\operatorname{CDDP}(0.1,0.25,0.5 \mu \mathrm{g} / \mathrm{mL})$, DOX $(25,50,100 \mathrm{ng} / \mathrm{mL})$ or ETO $(50,100,500 \mathrm{ng} / \mathrm{mL})$. Primordial and growing oocytes were counted in ovaries harvested after 7-day organ culture. Primordial oocytes are found in PMFs while larger growing oocytes are found in primary and secondary follicles present in 2-weeks-old ovaries. Data are expressed as mean $\pm \mathrm{SEM} ; * \mathrm{p}<0.05, * * \mathrm{p}<0.01$, $* * * \mathrm{p}<0.001, * * * * \mathrm{p}<0.0001$ (one-way ANOVA, Kruskal-Wallis with Dunn's multiple comparison test for nonparametric data). 
A

TAp63

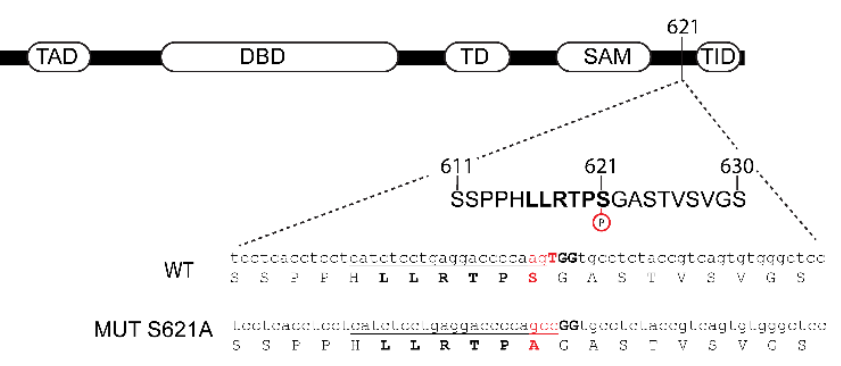

B

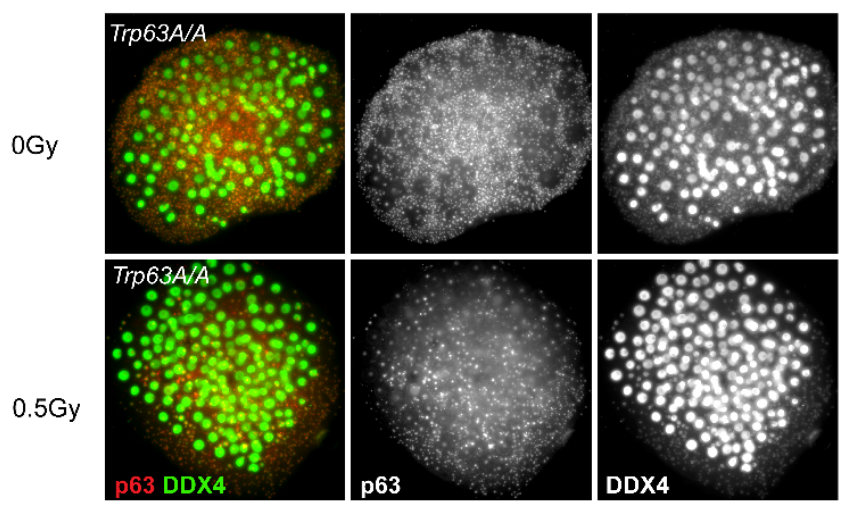

C

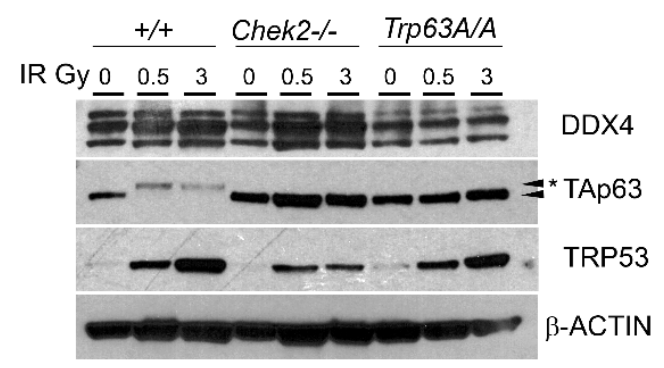

Figure S2. Mutation of 621 Serine to Alanine abolishes TAp63 phosphorylation and leads to its inactivation. (A) Schematic view TAp63 protein domain structure and localization of 621 Serine mutated by CRISPR-Cas9 editing. PAM site is shown in bold and sgRNA sequence is underlined. (B) Trp63A/A primordial oocytes show increased resistance to low dose of radiation $(0.5 \mathrm{~Gy})$. (C) Ovarian protein extracts were collected $3 \mathrm{hrs}$ after radiation with 0.5 and $3 \mathrm{~Gy}$ from wildtype Chek2-/- and Trp63A/A ovaries and were analyzed by western blot. TAp63 mobility shift is observed in wildtype ovaries (asterisk) but not in CHEK2 deficient or Trp63A/A mutant. TRP53 expression is detected following radiation even in the absence if CHEK2 although at lower level. 